\title{
LA EXPLOTACIÓN DEL HUEMUL (HIPPOCAMELUS BISULCUS, MOLINA 1782) EN LA PATAGONIA A LO LARGO DEL HOLOCENO
}

\author{
PABLO MARCELO FERNÁNDEZ ${ }^{a}$, ISABEL CRUZ ${ }^{b}$, JUAN BAUTISTA BELARDIc ${ }^{c}$ \\ MARIANA DE NIGRIS \& \& A. SEBASTIÁN MUÑOZ
}

\section{RESUMEN}

El objetivo de este trabajo es evaluar la explotación del huemul (Hippocamelus bisulcus) por parte de las poblaciones cazadoras en cuatro contextos ambientales patagónicos: el bosque andino, el ecotono bosqueestepa, el bosque asociado al litoral marino y la estepa. Específicamente, buscamos establecer si existieron diferencias en el lugar que ocupó este cérvido respecto de las otras especies utilizadas por estos cazadores, así como también las formas en que fue aprovechado a lo largo del Holoceno en cada uno de estos contextos. Utilizamos una base de datos de 73 sitios arqueológicos de Argentina y Chile que comprenden 112 registros con restos de la especie en sus secuencias estratigráficas. Los resultados muestran que la importancia del huemul en la subsistencia dependió de la estructura de recursos de cada ambiente y, por lo tanto, consideramos que el papel del huemul estuvo ligado a la historia de uso de los diferentes ambientes patagónicos durante el Holoceno. Holoceno.

PALABRAS CLAVE: Hippocamelus bisulcus, zooarqueología, cazadores-recolectores, Patagonia, EXPLOITATION IN PATAGONIA DURING THE HOLOCENE

\footnotetext{
ABSTRACT

This paper deals with hunter-gatherer's exploitation of huemul (Hippocamelus bisulcus) in four Patagonian environmental contexts: Andean forest, forest-steppe ecotone, forest-marine coast

a Instituto Nacional de Antropología y Pensamiento Latinoamericano (INAPL)- Consejo Nacional de Investigaciones Científicas y Técnicas (CONICET) - Universidad de Buenos Aires (UBA). 3 de febrero 1370, C1426BJN, Ciudad Autónoma de Buenos Aires, Argentina. Teléfono: 54-11-47843371. pablomarcelofernand@gmail.com; mariandenigris@yahoo.com.ar

b ICASUR - Unidad Académica Río Gallegos, Universidad Nacional de la Patagonia Austral (UARG-UNPA), Campus Universitario, Avenida Gregores y Piloto Lero Rivera s/n., 9400, Río Gallegos, Santa Cruz, Argentina. isabelzooarqueologia@gmail.com

c ICASUR - Unidad Académica Río Gallegos, Universidad Nacional de la Patagonia Austral (UARG-UNPA)/ Consejo Nacional de Investigaciones Científicas y Técnicas (CONICET). Campus Universitario, Avenida Gregores y Piloto Lero Rivera s/n., 9400, Río Gallegos, Santa Cruz, Argentina. juanbautistabelardi@gmail.com

d Laboratorio de Zooarqueología de Zonas Áridas - Instituto de Antropología de Córdoba (LaZTA-CONICET)/ Universidad Nacional de Córdoba. Av. H. Yrigoyen 174, 5000, Córdoba, Córdoba, Argentina. smunoz@conicet.gov.ar
} 
ecotone and steppe. More specifically, we discuss the place this cervid played among other faunal species used by Patagonian hunter-gatherers, as well as, the ways it was exploited in each of these environmental units throughout the Holocene. A 73 archaeological sites database from Argentina and Chile, with 112 huemul bone records from different stratigraphic sequences was considered. The results show that resource structure at each environmental context conditioned the way huemul was exploited and, hence, the way these environments were used along the Holocene account for huemul exploitation along time.

KEY WORDS: Hippocamelus bisulcus, zooarchaeology, hunter-gatherers, Patagonia, Holocene.

\section{INTRODUCCIÓN}

Las estrategias de subsistencia de los cazadores-recolectores de Patagonia se centraron en la explotación de un número limitado de especies faunísticas. El guanaco (Lama guanicoe) y los otáridos (Otaria flavescens y Arctocephalus australis) fueron las principales presas durante el Holoceno (Borrero, 1999, 2013; Muñoz, 2011; entre otros), en un contexto general de baja diversidad de mamíferos de tamaño medianogrande (Redford \& Eisenberg, 1992). Otras presas como el choique (Rhea pennata) y el huemul (Hippocamelus bisulcus), que por su tamaño corporal podrían haber sido explotadas con mayor frecuencia, tuvieron un papel menor en la subsistencia (Fernández, 2000; Fernández et al. 2015; Salemme \& Frontini, 2011, entre otros). En el caso del huemul, su papel marginal es llamativo no sólo porque su tamaño lo hace una presa apetecible sino porque, además, en ciertos sectores de Patagonia es el único vertebrado de alto rinde que puede explotarse (Arrigoni \& Fernández, 2004; Belardi \& Gómez Otero, 1998; Borrero, 1999, entre otros).

El huemul es un cérvido de tamaño mediano de aspecto robusto y extremidades cortas, con marcado dimorfismo sexual, expresado entre otros caracteres por las astas que exhiben los machos. Estas son cortas, bifurcadas en la base, casi verticales, usualmente con dos puntas por rama, la más larga de ellas alcanza en promedio $25 \mathrm{~cm}$. El peso de los machos varía entre 55-90 $\mathrm{kg}$ y las hembras entre $60-80 \mathrm{~kg}$. El pelaje es denso, grueso y frágil, y su coloración marrón oscura con tonalidades grises, rojas o amarillas favorece el camuflaje. Actualmente, el hábitat del huemul está relacionado con la Cordillera de los Andes y el bosque de Nothofagus sp. con escaso desarrollo de sotobosque. También utiliza los prados de altura y pedreros por encima de la línea de árboles. Sus poblaciones habitan entre el nivel de mar hasta los 2000 msnm. La organización social se caracteriza por grupos mixtos de pequeño tamaño y la unidad social básica está formada por el macho, la hembra y sus crías. El tamaño de los grupos presenta un rango de 1 a 5 individuos y en invierno se incrementa hasta 8 individuos. El ámbito de hogar o rango de acción es variable en función del grado de perturbación del hábitat (registros entre 36 y 490 ha). Los desplazamientos estacionales tienden a ser hacia cotas más bajas en invierno y hacia rangos más altos en verano (Vila et al. 2010).

Hasta el presente, el papel que tuvo el huemul en la subsistencia de las poblaciones de Patagonia fue abordado principalmente en escala local, ya sea a partir del estudio de sitios arqueológicos aislados o de un conjunto de ellos (De Nigris, 2004a, 2007; Fernández, 2008; Legoupil, 2000; Mena, 1992; San Román et al. 2002, entre otros). Por ejemplo, para el área de Meliquina (Neuquén, Argentina), se ha planteado la caza circunstancial u oportunista del huemul durante la mayor parte del año excepto durante la época de brama en el otoño, en la que habría sido planificada (Pérez \& Batres, 2008). En Cholila (Chubut, Argentina), sobre la base del conjunto óseo dominado por los restos de huemul recuperado en el sitio Cerro Pintado, se propuso la caza por encuentro de animales solitarios o grupos familiares de hasta tres individuos, posiblemente durante el invierno (Fernández, 2010). Un estudio sobre las técnicas de caza en esta localidad, que combina el análisis del registro óseo con la evidencia lítica, da sustento a esta primera hipótesis, sugiriendo además el 
empleo de armas arrojadizas, principalmente arco y flecha (Carballido \& Fernández, 2013). Una situación similar respecto de la caza de este ungulado fue documentada al norte de Cholila, en los valles de los ríos Manso inferior y Epuyén -Río Negro y Chubut, respectivamente, Argentina- (Fernández \& Carballido, 2015). Para la cuenca del río Ibáñez (Aisén, XI Región, Chile), también sobre la base de dos sitios dominados taxonómicamente por el huemul, se postuló la obtención planificada de este cérvido en el marco de un circuito de movilidad estacional, que incluía la caza en el ecotono bosque-estepa en el verano y en el bosque en el invierno (FuentesMucherl \& Mena, 2010; Mena, 1992; Velásquez \& Trejo, 2005). En otros casos ubicados en el actual ecotono bosque-estepa o en sus cercanías, como Alero Entrada Baker (Aisén) o Alero Destacamento Guardaparque (ADO; Santa Cruz, Argentina), la presencia de unos pocos restos óseos de huemul fue considerada evidencia de excursiones al bosque (Mena \& Jackson, 1991; Rindel, 2008), planteándose incluso el acarreo de la carne en cueros para disminuir los costos de transporte (Mena \& Jackson, 1991). También en el ecotono, los sitios Cerro Casa de Piedra Cuevas 5 y 7 (CCP5 y CCP7, Santa Cruz, Argentina) muestran que el huemul fue un recurso secundario en relación con el guanaco aunque ambos fueron aprovechados del mismo modo (De Nigris, 2004a, 2007). En CCP5 hay indicadores que sugieren que la explotación de este cérvido habría tenido lugar durante el otoño y el invierno (Reigadas, 2005). Su explotación también se dio en el marco de economías marítimas. En la costa pacífica del extremo sur de Chile, en los senos de Otway y Skyring, el huemul forma parte sistemática de las presas cazadas y su aporte en comparación con otros recursos en general es minoritario (Legoupil, 2000) aunque en dos sitios es la especie más representada (San Román et al. 2002).

En el marco de estas discusiones se generaron instrumentos metodológicos que permitieron una mejor aproximación al problema. Estos incluyen la elaboración de una anatomía económica (Belardi \& Gómez Otero, 1998) para estimar las formas de aprovechamiento y transporte, así como también la obtención de valores de isótopos estables de carbono y nitrógeno con el fin de evaluar el papel de la especie en la dieta de los cazadoresrecolectores (Fernández \& Tessone, 2014; Méndez et al. 2014; Tessone et al. 2014). La primera de estas herramientas mostró que los recursos brindados por el huemul -carne, grasa y médula- se distribuyen de modo similar que en el guanaco, por lo que no se esperaría que la selección y aprovechamiento de una u otra especie dependiera de este factor. Por su parte, los estudios isotópicos muestran una segregación entre los herbivoros que consumen plantas en el ambiente de bosque/ecotono bosque-estepa y aquéllos que lo hacen en la estepa, convirtiendo a los valores del carbono y especialmente a los del nitrógeno en marcadores geográficos. En el caso del huemul todas las muestras actuales y arqueológicas se asocian con el bosque y su ecotono con la estepa.

Otro de los aspectos que abordados fue la historia natural de la especie. Con el propósito de evaluar hipótesis acerca de su distribución durante el Holoceno y explorar los efectos de sus interacciones con las poblaciones cazadorasrecolectoras discutimos, en un trabajo anterior, la evidencia acerca de la presencia de restos de huemul en contextos arqueológicos sobre la base de las publicaciones realizadas hasta el año 2013 (Fernández et al. 2015). Los resultados mostraron que este cérvido no tuvo una distribución muy diferente a la reconstruida para tiempos históricos, fundamentalmente asociada al bosque andino patagónico y su ecotono con la estepa. Además pudimos comprobar que, si bien el huemul fue un recurso disponible desde los primeros momentos del poblamiento humano -tal como atestigua el registro paleontológico-, fue cazado con mayor intensidad desde el Holoceno medio. Asimismo, a pesar de que sus restos son más abundantes en los contextos correspondientes a los últimos 2.200 años AP, la predación ejercida por los cazadores-recolectores habría tenido escasa o nula influencia sobre la distribución de la especie en una escala regional.

En este trabajo el objetivo es ampliar la discusión previa (Fernández et al. 2015) y evaluar la explotación del huemul en cuatro contextos 

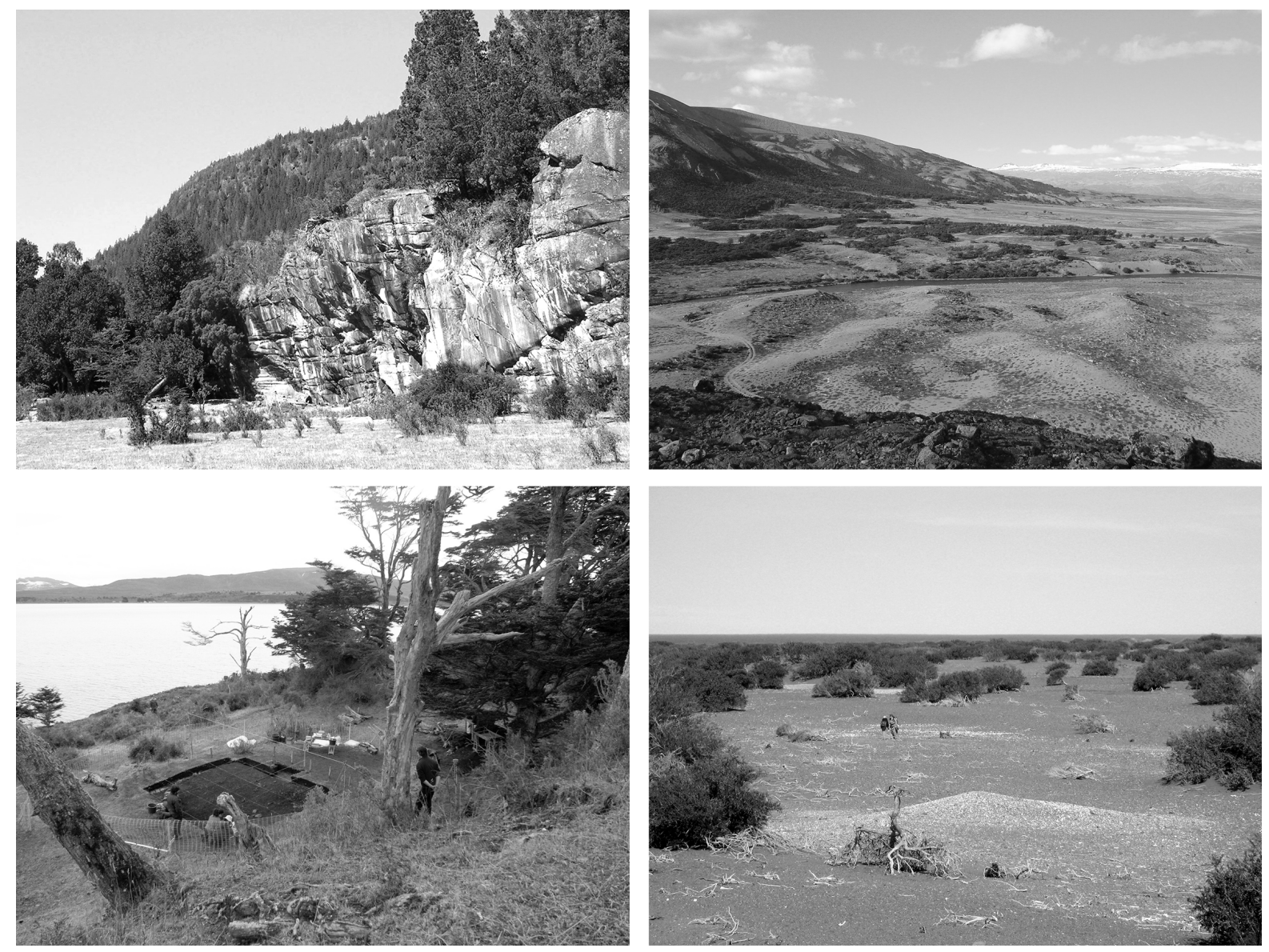

Fig. 1. Contextos ambientales considerados relevantes para el estudio del aprovechamiento del huemul. Arriba: Izquierda, bosque que rodea al sitio Paredón Lanfré (Río Negro, Argentina); Derecha, ecotono bosque-estepa, vista desde el sitio Cerro Casa de Piedra 7 (Santa Cruz, Argentina).

Abajo: Izquierda, bosque asociado al litoral marino en la localidad arqueológica Punta Santa Ana (XII Región, Chile); Derecha, ambiente de estepa arbustiva asociado al sitio P 35 (Santa Cruz, Argentina). Fotografías de los autores, excepto la de Punta Santa Ana, cedida por Manuel San Román.

ambientales que identificamos como significativos desde el punto de vista del aprovechamiento de la fauna por parte de las poblaciones cazadoras a partir de la estructura de recursos que presentan: el bosque andino, el ecotono bosque-estepa, el bosque asociado al litoral marino y la estepa (Fig. 1). Específicamente buscamos establecer si existieron diferencias en el lugar que ocupó el huemul respecto de las otras especies utilizadas en cada uno de estos ambientes y en las formas de su aprovechamiento a lo largo del Holoceno.

\section{METODOLOGÍA}

La base de datos a partir de la cual se desarrolla este trabajo incluye la información sobre restos de huemul presentes en contextos arqueológicos de Argentina y Chile publicada hasta el año 2014 inclusive. La información recopilada incluye los sitios arqueológicos de donde provienen las muestras, su ubicación geográfica, cronología, ambiente actual y el papel otorgado al huemul con respecto a otros taxones recuperados en esos mismos sitios. En términos de su aprovechamiento, los datos recabados son dispares debido a que sólo una fracción de los trabajos consultados corresponde a estudios zooarqueológicos. De allí, por ejemplo, que una parte de los registros sólo proporciona información cualitativa, limitada a la presencia de restos de huemul en el conjunto 
óseo. Otros estudios, si bien incluyen información cuantitativa carecen de otros detalles, como la representación de partes esqueletarias o la presencia de modificaciones óseas. En consecuencia, para la discusión privilegiamos estudios más detallados, integrando el resto de los datos cada vez que fue posible. Esta disparidad también se observa en la evaluación tafonómica de los conjuntos, disponible sólo para un escaso número de los sitios relevados. A pesar del sesgo que podrían introducir estas discrepancias decidimos tomar esta información tal como es presentada por los autores. Es esperable que el tamaño de la muestra analizada, que abarca toda la Patagonia de Argentina y Chile, nos permita identificar patrones significativos en términos de la subsistencia humana que no serían visibles a partir de muestras más pequeñas.

Comomedidasdecuantificaciónconsideramos el NISP y el MNI (Lyman, 2008) publicados por los diferentes autores a partir de los cuales volvimos a calcular el NISP general de cada depósito, excluyendo los especímenes del Orden Rodentia debido a que generalmente en estos contextos sus huesos no son producto del consumo humano y, además, no están incluidos en todos los listados faunísticos publicados. Su incorporación en las comparaciones disminuiría artificiosamente la relación entre el huemul y las demás especies representadas. Lo mismo ocurre con las valvas de moluscos, que tampoco tuvimos en cuenta en la cuantificación. Asimismo, tampoco incluimos categorías taxonómicas más abarcativas como Mammalia o mamíferos, aún cuando los autores hayan empleado una división por tamaño (e. g. mamíferos pequeños, medianos y grandes). Por otra parte, consideramos los registros de Cervidae cuando los autores evalúan que los restos probablemente corresponden a huemul.
Dado que las muestras provienen de diferentes tipos de sitios, cada unidad estratigráfica con restos de huemul fue analizada como un registro individual, de forma tal que estudiamos cada unidad de manera independiente aunque proceda del mismo sitio. Los datos de la localización ambiental de los sitios fueron tomados de la bibliografía y corresponden al ambiente actual. En los casos en los que la publicación no incluía datos sobre el mismo, ubicamos el sitio en las imágenes satelitales del programa Google Earth para constatar las características ambientales. A la vez, si la información paleoambiental estaba disponible, fue considerada para la discusión.

Para el análisis cronológico segmentamos el Holoceno siguiendo la propuesta de Walker et al. (2012), a la que le agregamos subdivisiones para una mejor evaluación de las posibles variaciones (Tabla 1). Cuando la cronología publicada para un registro abarcaba más de una de estas divisiones (por ejemplo, "Holoceno" o "6.900 al presente") no la incluimos en el análisis cronológico aunque sí en el de abundancia taxonómica. Cuatro registros no fechados del sitio CCP7 fueron asignados al HM2 (un registro) y al HTe2 (los tres restantes), ya que estaban entre registros datados en esos lapsos. Para la asignación cronológica de otros cuatro registros (Punta Eugenia 2, Caleta Alonso, Martín Pescador 2, Puesto La Sal) nos basamos en la altura del sitio sobre el nivel del mar, siguiendo el criterio planteado por los autores (San Román et al. 2002).

\section{RESULTADOS}

El análisis de la información publicada da cuenta de la presencia de sitios arqueológicos con restos de huemul entre $38^{\circ} 53^{-} \mathrm{S}$ y $53^{\circ} 37^{-} \mathrm{S}$, abarcando aproximadamente unos $1640 \mathrm{~km}$ en

Tabla 1. Segmentos cronológicos considerados en el análisis.

\begin{tabular}{lll}
\hline Lapso & Abreviatura & Cronología (años AP sin calibrar) \\
\hline Holoceno Temprano 1 & HTe1 & $11.700-9.950$ \\
Holoceno Temprano 2 & HTe2 & $9.949-8.200$ \\
Holoceno Medio 1 & HM1 & $8.199-6.200$ \\
Holoceno Medio 2 & HM2 & $6.199-4.200$ \\
Holoceno Tardío 1 & HTa1 & $4.199-2.200$ \\
Holoceno Tardío 2 & HTa2 & 2.199 al presente \\
\hline
\end{tabular}




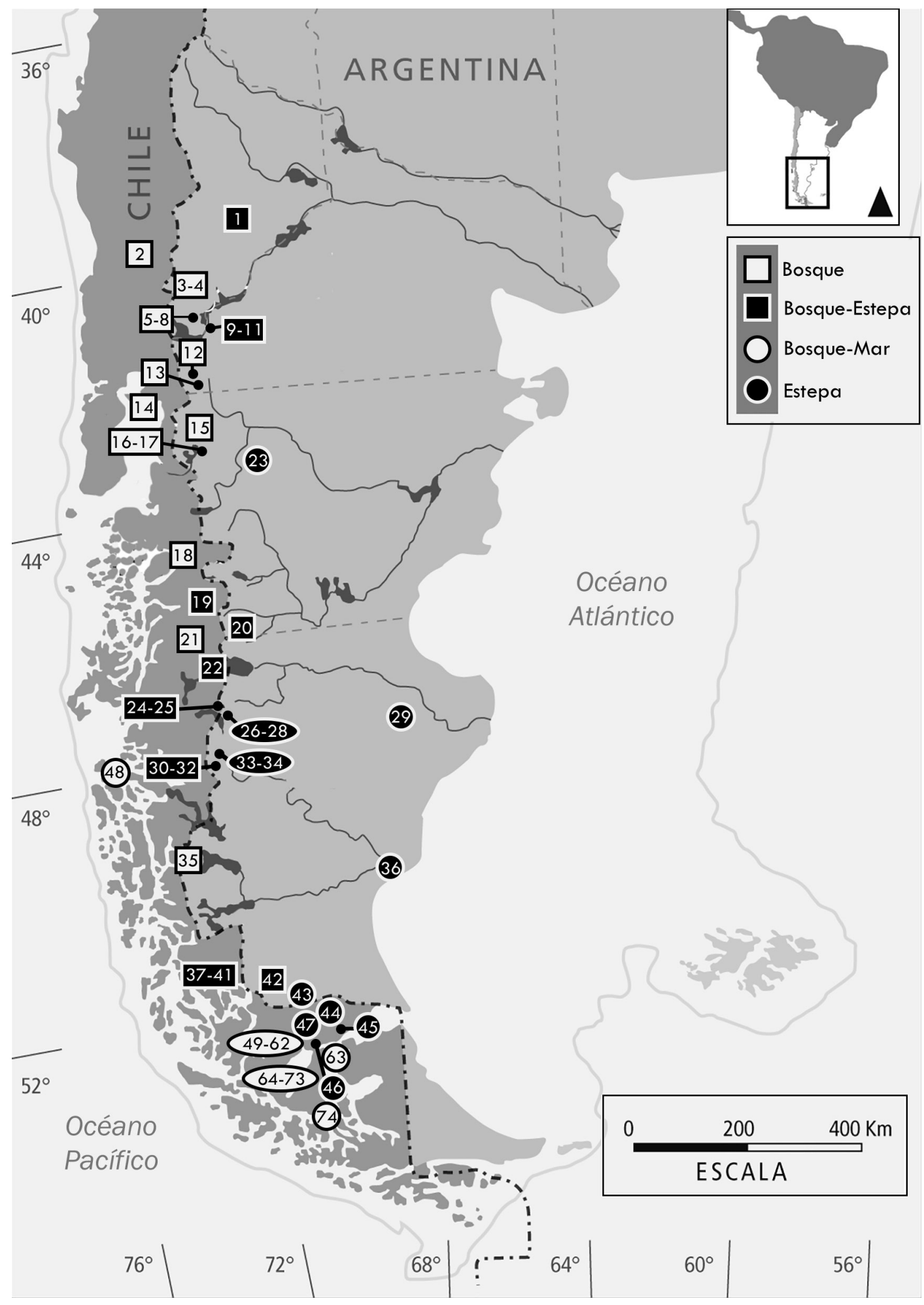

Fig. 2. Localización de los sitios incluidos en el análisis, organizados por contexto ambiental. Las referencias numéricas corresponden a las listadas en las Tablas 2 a 5. 
línea recta, cubriendo la totalidad de Patagonia a excepción de Tierra del Fuego, sector no habitado por esta especie (Fig. 2). Para discutir la explotación del huemul por los cazadores-recolectores utilizamos 73 sitios que comprenden 112 registros con restos de la especie en sus secuencias estratigráficas. El registro más septentrional es el del sitio Alero IV del Tromen (Neuquén, Argentina), ubicado en el ecotono entre el bosque de araucaria (Araucaria araucana) y la estepa, y el más meridional es Punta Santa Ana 3 (Magallanes, XII Región, Chile), ubicado sobre el estrecho de Magallanes. El registro más antiguo proviene del nivel basal del Alero El Trébol (Río Negro, Argentina), datado ca. 10.600 años AP (Hajduk et al. 2012) y los más recientes datan de tiempos históricos (por ejemplo Laguna Cóndor, Santa Cruz, Argentina; L’Heureux, 2014). La mayor parte de los registros corresponde a sitios ubicados en espacios ecotonales, ya sea entre el bosque y la estepa como entre el bosque y la costa marina. Los registros exclusivamente de bosque alcanzan el $22 \%$ y los de la estepa actual el $15 \%$ (Fig. 3).

\section{La explotación del huemul en el bosque}

Las evidencias de explotación de este cérvido provenientes de sitios ubicados en el bosque actual incluyen registros entre $39^{\circ} 30^{-} \mathrm{S}$ y $49^{\circ} 19^{\prime} \mathrm{S}$, distribuidos a lo largo de una estrecha franja que tiene como puntos extremos $72^{\circ} 16^{\circ}$ $\mathrm{O}$ y $72^{\circ} 53^{\prime} \mathrm{O}$. De los 24 registros procedentes de 16 sitios, 21 tienen asignación cronológica y en conjunto abarcan todo el Holoceno (Figura 4a). Como ya señalamos, los más antiguos fueron hallados en el sitio Alero El Trébol (Tabla 2) y datan de ca. 10.600 años AP, momento en el que el alero estaba emplazado en un ambiente de bosque abierto de Nothofagus tipo dombeyi asociado a una vegetación herbácea tipo gramíneas (Whithlock et al. 2006). Esta ocupación inicial se habría dado en un contexto de exploración del bosque por poblaciones que también hacían uso de la estepa (Lezcano et al. 2010). El conjunto faunístico es variado y, además del aprovechamiento del huemul, se registró la explotación de zorros (Lycalopex culpaeus y Dusicyon avus), milodón, ciervo extinto de tamaño comparable al actual Blastocerus dichotomus y aves (tamaños Pteroptochos y Cygnus). Hay tres especímenes óseos de guanaco, pero no tienen evidencias de faenamiento (Lezcano et al. 2010). Las características del conjunto óseo, en especial el tamaño de muestra, impiden mayores precisiones sobre el procesamiento del huemul; el único dato es que uno de los 12 especímenes

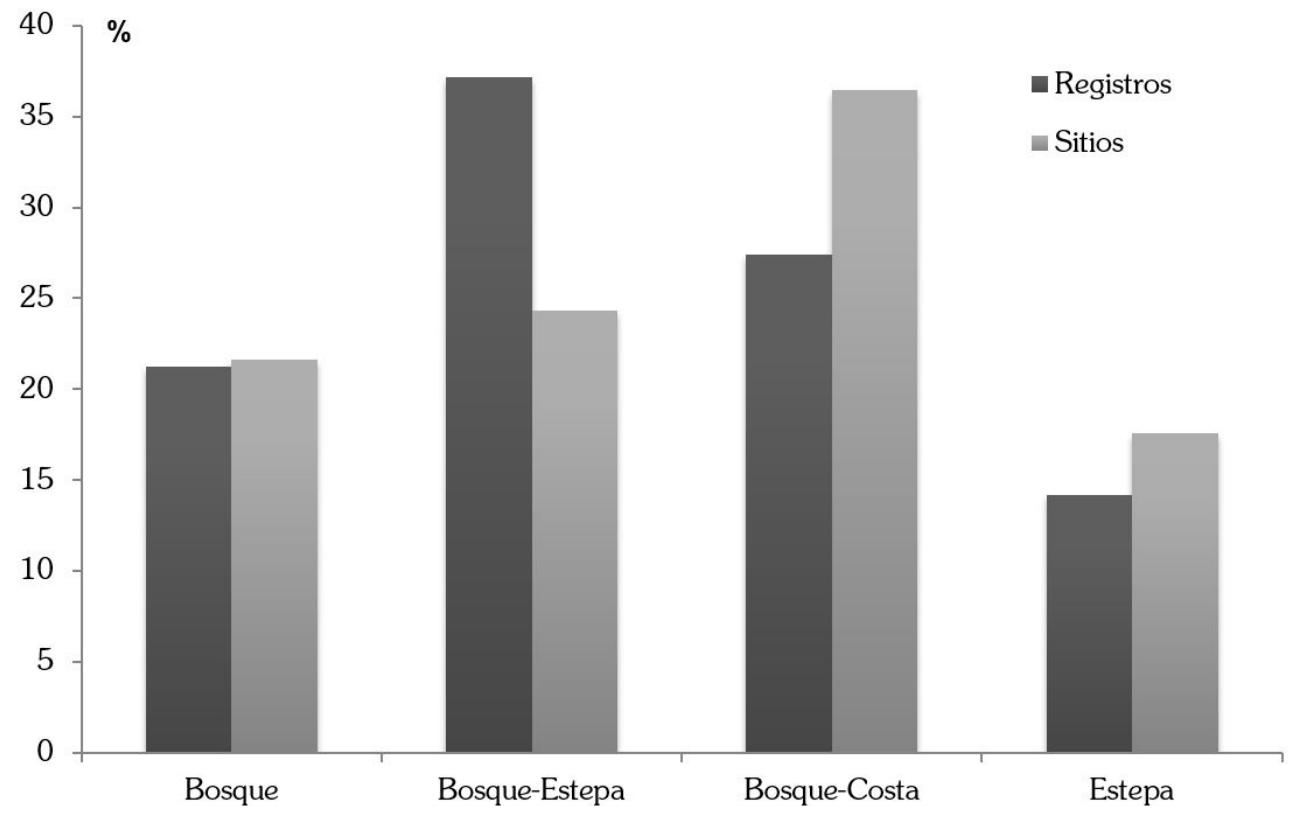

Fig. 3. Frecuencia relativa de sitios y registros con restos de huemul por unidad ambiental. 


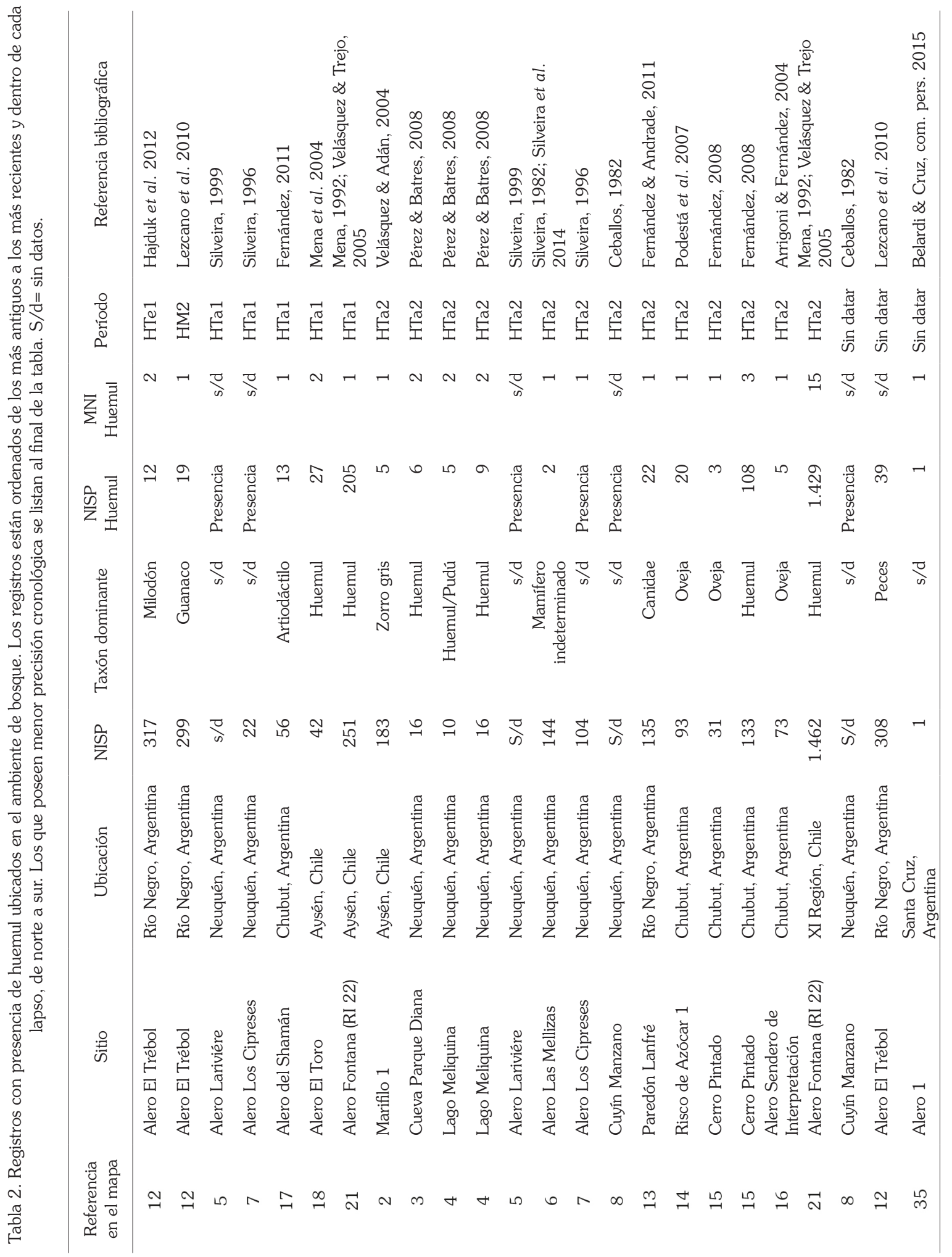



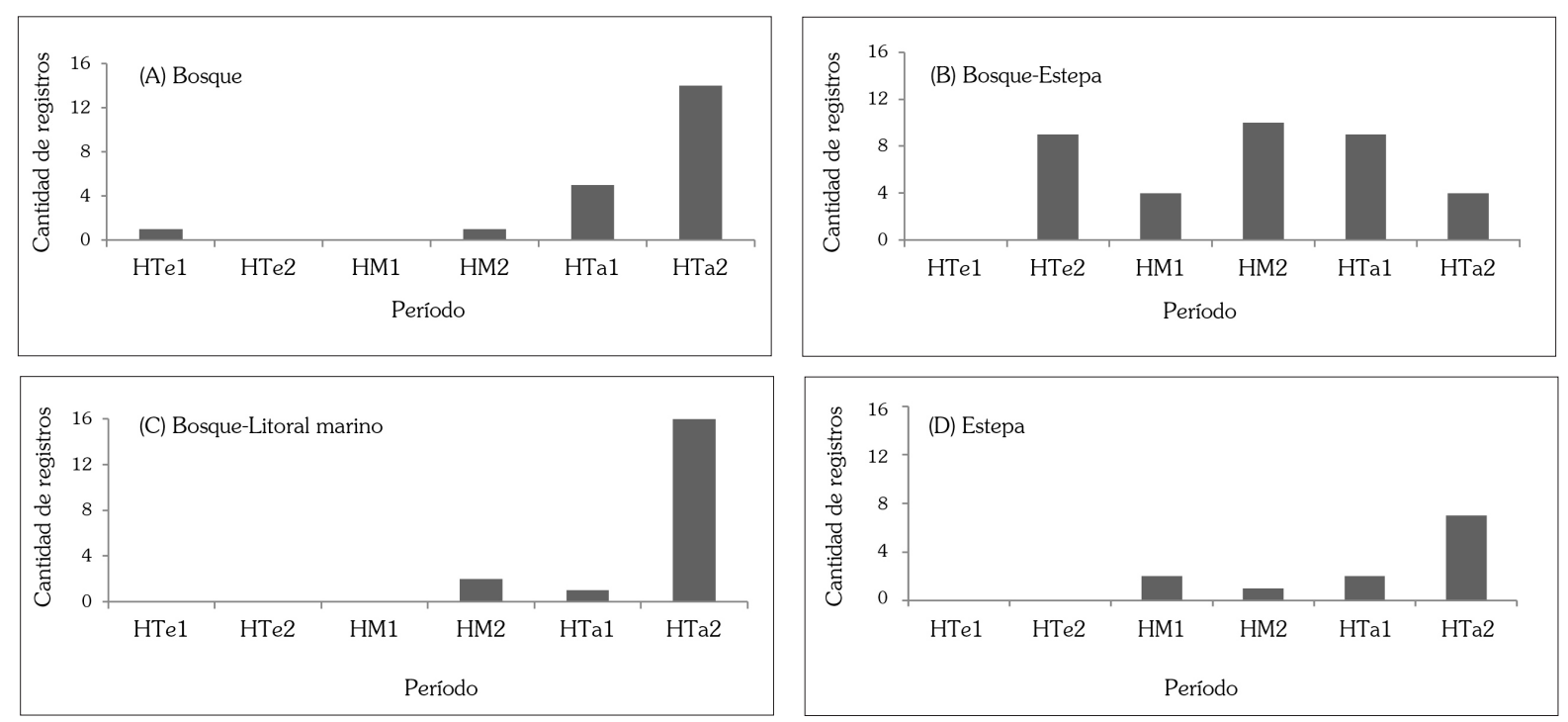

Fig. 4. Cantidad de registros con restos de huemul en cada unidad ambiental. A: bosque,

B: ecotono bosque-estepa, C: bosque asociado al litoral marino y D: estepa.

identificados, un astrágalo, posee huellas de corte (Hajduk et al. 2004).

Para el período HM2 el único registro también proviene del sitio Alero El Trébol y está datado en ca. 5.600-5.800 años AP (Tabla 2). En ese momento el sitio estaba ubicado en un bosque abierto de Nothofagus con estrato arbustivo. Se trataría de ocupaciones que reflejan estancias más prolongadas dentro del bosque, por parte de grupos que habitaban la estepa (Lezcano et al. 2010). Además del huemul, las especies aprovechadas incluyen guanaco, que es el ungulado más representado, zorro colorado, roedores, peces y aves. De los 19 especímenes de huemul determinados dos presentan modificaciones antrópicas en forma de corte. Los restos de guanaco son más numerosos (NISP 92) y también poseen este tipo de huellas (Lezcano et al. 2010). La falta de otros datos, por ejemplo la composición anatómica, nos impide evaluar si existió un aprovechamiento diferencial de estos ungulados.

Los últimos 4.200 años AP (Holoceno tardío) concentran la evidencia sobre la explotación del huemul en el bosque, que es el taxón dominante en buena parte de los conjuntos. Para este lapso se contabilizan cinco registros para el HTa1 y 14 para el HTa2, que totalizan el 90\% (Fig. 4). De estos 19 registros, 13 proveen información zooarqueológica, esto es, han sido objeto de análisis específicos y proporcionan más datos que la presencia de la especie. Se trata de muestras pequeñas que, exceptuando los registros de Alero Fontana, poseen un NISP general que no supera los 200 especímenes y en los que el huemul está representado por pocos restos. Asimismo, en cuatro de estos conjuntos el taxón dominante corresponde a materiales intrusivos: oveja (Ovis aries) en Risco de Azócar 1 (Chubut, Argentina), en el nivel de superficie de Cerro Pintado y en el Alero del Sendero de Interpretación (Chubut, Argentina) y un cánido en Paredón Lanfré (Río Negro, Argentina) (Tabla 2). En efecto, el huemul es el taxón dominante en siete conjuntos, elevándose a 12 al dejar de lado las especies introducidas y las categorías taxonómicas de grano grueso, como Artiodáctilo. La excepción corresponde a Marifilo 1 (Velásquez \& Adán, 2004), con mayoría de restos de zorro gris (Lycalopex griseus) y muy pocos especímenes de huemul (Tabla 2).

Los estudios llevados a cabo en los dos sitios en los que el huemul supera los 100 especímenes óseos (Cerro Pintado y Alero Fontana) permiten aproximarnos a la modalidad de explotación del huemul, incluyendo las estrategias de caza en el bosque (Carballido \& Fernández, 2013; Velásquez \& Trejo, 2005). La caza por encuentro estaría registrada en Cerro Pintado, sitio al que ingresaron animales cazados en las cercanías, en 
el que las presas fueron procesadas y en el que se reacondicionaron las armas empleadas para su obtención (Carballido \& Fernández, 2013). En cambio, se propuso que en Alero Fontana la caza del huemul habría sido planificada en el marco de un circuito de movilidad estacional (Mena, 1992; Velásquez \& Trejo, 2005). Al igual que en Cerro Pintado, la captura de las presas habría tenido lugar en las inmediaciones del sitio, que se ubica en las cercanías del lago Lapparent. Es posible que se aprovechara el descenso de los huemules a los valles ubicados en cotas bajas durante el invierno y la concentración de animales en los bordes de cuerpos de agua. Aparentemente, esto estaría relacionado con las estrategias antipredador del huemul, que por su aptitud para nadar utiliza ríos y lagos como vías de escape. Entonces, dicha concentración invernal podria haber sido aprovechada por los cazadores-recolectores, tal como lo hacen los pumas en la actualidad (Fernández \& Forlano, 2009). En un trabajo previo (Fernández et al. 2015) interpretamos al Alero Fontana como un ejemplo de caza oportunista. Es necesario aclarar que utilizamos este concepto en el sentido de Jaksic (1989), esto es, que las presas se cazan en la misma proporción en las que están disponibles en un ambiente dado. La concentración de huemules en las márgenes del lago Lapparent explicaría el inusual número de individuos (MNI 15) registrados en los niveles más tardíos (340690 años AP) de este sitio. En otras palabras, los cazadores estarían seleccionando un espacio más que una presa específica, de allí el oportunismo al que hacemos referencia.

\section{La explotación del huemul}

en el ecotono bosque-estepa

En esta unidad ambiental las evidencias de explotación del huemul se distribuyen espacialmente entre aproximadamente $38^{\circ} 53^{\prime} \mathrm{S}$ y $51^{\circ} 54^{\prime} \mathrm{S}$. En este extenso gradiente latitudinal, la estrecha franja transicional del ecotono bosque-estepa presenta sitios entre los puntos longitudinales extremos de $70^{\circ}$ $27^{\prime} \mathrm{O}$ y $72^{\circ} 57^{\prime} \mathrm{O}$. La cantidad de sitios $(\mathrm{N}=18)$ es similar a la observada en el bosque $(\mathrm{N}=16)$ aunque en el ecotono-bosque estepa hay más registros (Tabla 3), que abarcan entre ca. 9.700 años AP (HTe2) y tiempos históricos (HTa2) (Fig. 4B).
Entre los registros se destacan por su cantidad y rango temporal los del Cerro Casa de Piedra. Los sitios CCP5 y CCP7 aportan en conjunto 21 registros, que cubren aproximadamente 7.200 años (Tabla 3). En ellos, el huemul integra el grupo de los recursos complementarios al guanaco, manteniendo un aporte constante que osciló entre 1\% y $10 \%$ a lo largo de toda la secuencia. Los conjuntos de estos sitios reflejan el aprovechamiento exhaustivo de todos los recursos alimenticios proporcionados por el huemul. Además, muestran que a pesar de la contribución diferencial a la subsistencia, guanaco y huemul exhiben una intensidad de procesamiento similar (De Nigris, 2004 a y b, 2007; De Nigris et al. 2010).

La imagen uniforme de los conjuntos de CCP tiene su contrapunto en otros registros del ecotono bosque-estepa que sugieren una estrategia de explotación diferente. Tal es el caso de los niveles HM2 y HTa2 del Alero Las Guanacas (XI Región, Chile), que muestran el predominio del huemul por sobre el guanaco y escasas huellas de procesamiento (Fuentes-Mucherl \& Mena, 2010). Como hemos visto, en los sitios emplazados en el bosque, los conjuntos dominados por el huemul reflejan la disponibilidad diferencial de ungulados en ese ambiente. Cabe preguntarnos si la importancia taxonómica del huemul se debe a que el Alero Las Guanacas estuvo ubicado en el bosque en estos lapsos. Si bien los ejemplos de cambios en la posición de la franja ecotonal entre el bosque y la estepa durante el Holoceno son numerosos (de Porras et al. 2012; Iglesias et al. 2012; Markgraf et al. 2007, entre otros), no existen registros paleoambientales para la cuenca del Ibáñez que avalen la hipótesis. Como ya mencionamos, los investigadores de esta cuenca propusieron que el Alero Las Guanacas formó parte de un circuito de movilidad estacional en el valle del río Ibáñez que implicaba la obtención planificada del huemul a lo largo de un ciclo anual, con captura invernal en el bosque (Alero Fontana) y estival en el ecotono bosque-estepa (Alero Las Guanacas, FuentesMucherl \& Mena, 2010). El Alero Los Carneros fue considerado un ejemplo del aprovechamiento de recursos de distintos microambientes (Mena \& López, 2014). En este sitio, ubicado en un paisaje de estepa graminosa cercano a bosques de falda, se recuperaron 17 especímenes óseos de huemul en 
Tabla 3. Registros con presencia de huemul ubicados en el ambiente de ecotono bosque-estepa. Los registros están ordenados de los más antiguos a los más recientes y dentro de cada lapso, de norte a sur. Los que poseen menor precisión cronológica se listan al final de la tabla. $\mathrm{S} / \mathrm{d}=$ sin datos.

\begin{tabular}{|c|c|c|c|c|c|c|c|c|}
\hline $\begin{array}{c}\text { Referencia } \\
\text { en el } \\
\text { mapa }\end{array}$ & Sitio & Ubicación & NISP & $\begin{array}{c}\text { Taxón } \\
\text { dominante }\end{array}$ & $\begin{array}{c}\text { NISP } \\
\text { Huemul }\end{array}$ & $\begin{array}{c}\text { MNI } \\
\text { Huemul }\end{array}$ & Período & $\begin{array}{l}\text { Referencia } \\
\text { bibliográfica }\end{array}$ \\
\hline 19 & $\begin{array}{l}\text { Cueva Baño } \\
\text { Nuevo } 1\end{array}$ & Aysén, Chile & 31 & Guanaco & Presencia & 1 & HTe2 & $\begin{array}{l}\text { Velásquez \& Mena, } \\
2006\end{array}$ \\
\hline 32 & $\begin{array}{l}\text { Cerro Casa de } \\
\text { Piedra, Cueva } 7\end{array}$ & $\begin{array}{l}\text { Santa Cruz, } \\
\text { Argentina }\end{array}$ & 617 & Guanaco & 27 & 2 & HTe2 & De Nigris, 2004b \\
\hline 32 & $\begin{array}{l}\text { Cerro Casa de } \\
\text { Piedra Cueva } 7\end{array}$ & $\begin{array}{l}\text { Santa Cruz, } \\
\text { Argentina }\end{array}$ & 946 & Artiodáctilo & 55 & 2 & HTe2 & De Nigris, 2004b \\
\hline 32 & $\begin{array}{l}\text { Cerro Casa de } \\
\text { Piedra Cueva } 7\end{array}$ & $\begin{array}{l}\text { Santa Cruz, } \\
\text { Argentina }\end{array}$ & 722 & Guanaco & 26 & 1 & HTe2 & De Nigris, 2004b \\
\hline 32 & $\begin{array}{l}\text { Cerro Casa de } \\
\text { Piedra Cueva } 7\end{array}$ & $\begin{array}{l}\text { Santa Cruz, } \\
\text { Argentina }\end{array}$ & 835 & Guanaco & 33 & 2 & $\mathrm{HTe} 2$ & De Nigris, 2004b \\
\hline 32 & $\begin{array}{l}\text { Cerro Casa de } \\
\text { Piedra Cueva } 7\end{array}$ & $\begin{array}{l}\text { Santa Cruz, } \\
\text { Argentina }\end{array}$ & 294 & Artiodáctilo & 5 & 1 & HTe2 & De Nigris, 2004b \\
\hline 32 & $\begin{array}{l}\text { Cerro Casa de } \\
\text { Piedra Cueva } 7\end{array}$ & $\begin{array}{l}\text { Santa Cruz, } \\
\text { Argentina }\end{array}$ & 856 & Artiodáctilo & 14 & 1 & HTe2 & $\begin{array}{l}\text { De Nigris et al. } \\
2010\end{array}$ \\
\hline 32 & $\begin{array}{l}\text { Cerro Casa de } \\
\text { Piedra Cueva } 7\end{array}$ & $\begin{array}{l}\text { Santa Cruz, } \\
\text { Argentina }\end{array}$ & 684 & Artiodáctilo & 10 & 1 & $\mathrm{HTe} 2$ & $\begin{array}{l}\text { De Nigris et al. } \\
2010\end{array}$ \\
\hline 32 & $\begin{array}{l}\text { Cerro Casa de } \\
\text { Piedra Cueva } 7\end{array}$ & $\begin{array}{l}\text { Santa Cruz, } \\
\text { Argentina }\end{array}$ & 653 & Artiodáctilo & 4 & 1 & $\mathrm{HTe} 2$ & $\begin{array}{l}\text { De Nigris et al. } \\
2010\end{array}$ \\
\hline 19 & $\begin{array}{l}\text { Cueva Baño Nuevo } \\
1\end{array}$ & Aysén, Chile & 85 & Guanaco & Presencia & 1 & HM1 & $\begin{array}{l}\text { Velásquez \& Mena, } \\
2006\end{array}$ \\
\hline 20 & Casa de Piedra 1 & $\begin{array}{l}\text { Chubut, } \\
\text { Argentina }\end{array}$ & $\mathrm{s} / \mathrm{d}$ & Guanaco & Presencia & $\mathrm{s} / \mathrm{d}$ & HM1 & $\begin{array}{l}\text { Pérez de Micou et } \\
\text { al. } 2014\end{array}$ \\
\hline 31 & $\begin{array}{l}\text { Cerro Casa de } \\
\text { Piedra Cueva } 5\end{array}$ & $\begin{array}{l}\text { Santa Cruz, } \\
\text { Argentina }\end{array}$ & 370 & Guanaco & 40 & 2 & HM1 & De Nigris, 2007 \\
\hline 32 & $\begin{array}{l}\text { Cerro Casa de } \\
\text { Piedra Cueva } 7\end{array}$ & $\begin{array}{l}\text { Santa Cruz, } \\
\text { Argentina }\end{array}$ & 309 & Artiodáctilo & 13 & 1 & HM1 & De Nigris, 2004b \\
\hline 1 & $\begin{array}{l}\text { Alero IV del } \\
\text { Tromen }\end{array}$ & $\begin{array}{l}\text { Neuquén, } \\
\text { Argentina }\end{array}$ & 219 & Guanaco & 1 & 1 & HM2 & $\begin{array}{l}\text { Perrota \& Pereda, } \\
1987\end{array}$ \\
\hline 10 & Traful 1 & $\begin{array}{l}\text { Neuquén, } \\
\text { Argentina }\end{array}$ & 1.606 & Guanaco & 2 & 1 & HM2 & Cordero, 2010 \\
\hline 20 & Casa de Piedra 1 & $\begin{array}{l}\text { Chubut, } \\
\text { Argentina }\end{array}$ & $\mathrm{s} / \mathrm{d}$ & Guanaco & Presencia & $\mathrm{s} / \mathrm{d}$ & HM2 & $\begin{array}{l}\text { Pérez de Micou et } \\
\text { al. } 2014\end{array}$ \\
\hline 22 & $\begin{array}{l}\text { Alero Las Guanacas } \\
\text { (RI 16) }\end{array}$ & Aysén, Chile & 488 & Artiodáctilo & 32 & 3 & HM2 & $\begin{array}{l}\text { Fuentes-Murchel \& } \\
\text { Mena, } 2010\end{array}$ \\
\hline 31 & $\begin{array}{l}\text { Cerro Casa de } \\
\text { Piedra Cueva } 5\end{array}$ & $\begin{array}{l}\text { Santa Cruz, } \\
\text { Argentina }\end{array}$ & 712 & Guanaco & 27 & 1 & HM2 & De Nigris, 2007 \\
\hline 32 & $\begin{array}{l}\text { Cerro Casa de } \\
\text { Piedra Cueva } 7\end{array}$ & $\begin{array}{l}\text { Santa Cruz, } \\
\text { Argentina }\end{array}$ & 465 & Guanaco & 31 & 2 & HM2 & De Nigris, 2004b \\
\hline 32 & $\begin{array}{l}\text { Cerro Casa de } \\
\text { Piedra Cueva } 7\end{array}$ & $\begin{array}{l}\text { Santa Cruz, } \\
\text { Argentina }\end{array}$ & 649 & Guanaco & 6 & 1 & HM2 & De Nigris, 2004b \\
\hline 32 & $\begin{array}{l}\text { Cerro Casa de } \\
\text { Piedra Cueva } 7\end{array}$ & $\begin{array}{l}\text { Santa Cruz, } \\
\text { Argentina }\end{array}$ & 1.870 & Guanaco & 71 & 1 & HM2 & De Nigris, 2004b \\
\hline
\end{tabular}




\begin{tabular}{|c|c|c|c|c|c|c|c|c|}
\hline $\begin{array}{c}\text { Referencia } \\
\text { en el } \\
\text { mapa }\end{array}$ & Sitio & Ubicación & NISP & $\begin{array}{c}\text { Taxón } \\
\text { dominante }\end{array}$ & $\begin{array}{l}\text { NISP } \\
\text { Huemul }\end{array}$ & $\begin{array}{l}\text { MNI } \\
\text { Huemul }\end{array}$ & Período & $\begin{array}{c}\text { Referencia } \\
\text { bibliográfica }\end{array}$ \\
\hline 32 & $\begin{array}{l}\text { Cerro Casa de } \\
\text { Piedra Cueva } 7\end{array}$ & $\begin{array}{l}\text { Santa Cruz, } \\
\text { Argentina }\end{array}$ & 504 & Guanaco & 13 & 1 & HM2 & De Nigris, 2004b \\
\hline 32 & $\begin{array}{l}\text { Cerro Casa de } \\
\text { Piedra Cueva } 7\end{array}$ & $\begin{array}{l}\text { Santa Cruz, } \\
\text { Argentina }\end{array}$ & 758 & Guanaco & 30 & 1 & HM2 & De Nigris, 2004b \\
\hline 32 & $\begin{array}{l}\text { Cerro Casa de } \\
\text { Piedra Cueva } 7\end{array}$ & $\begin{array}{l}\text { Santa Cruz, } \\
\text { Argentina }\end{array}$ & 301 & Guanaco & 9 & 1 & HM2 & De Nigris, 2004b \\
\hline 10 & Traful 1 & $\begin{array}{l}\text { Neuquén, } \\
\text { Argentina }\end{array}$ & 278 & Guanaco & 9 & 1 & HTa1 & Cordero, 2010 \\
\hline 24 & Alero Gianella & Aysén, Chile & 747 & $\begin{array}{l}\text { Artiodáctilo/ } \\
\text { Guanaco }\end{array}$ & 9 & 1 & HTa1 & $\begin{array}{l}\text { Fuentes-Murchel et } \\
\text { al. } 2012\end{array}$ \\
\hline 31 & $\begin{array}{l}\text { Cerro Casa de } \\
\text { Piedra Cueva } 5\end{array}$ & $\begin{array}{l}\text { Santa Cruz, } \\
\text { Argentina }\end{array}$ & 280 & Guanaco & 8 & 1 & HTa1 & De Nigris, 2007 \\
\hline 31 & $\begin{array}{l}\text { Cerro Casa de } \\
\text { Piedra Cueva } 5\end{array}$ & $\begin{array}{l}\text { Santa Cruz, } \\
\text { Argentina }\end{array}$ & 1.026 & Guanaco & 48 & 2 & HTa1 & De Nigris, 2007 \\
\hline 32 & $\begin{array}{l}\text { Cerro Casa de } \\
\text { Piedra Cueva } 7\end{array}$ & $\begin{array}{l}\text { Santa Cruz, } \\
\text { Argentina }\end{array}$ & 786 & Artiodáctilo & 33 & 2 & HTa1 & De Nigris, 2004b \\
\hline 37 & Dos Herraduras 1 & $\begin{array}{l}\text { Magallanes, } \\
\text { Chile }\end{array}$ & $\mathrm{s} / \mathrm{d}$ & $\mathrm{s} / \mathrm{d}$ & Presencia & $\mathrm{s} / \mathrm{d}$ & HTa1 & Borrero, 1980 \\
\hline 38 & Dos Herraduras 2 & $\begin{array}{l}\text { Magallanes, } \\
\text { Chile }\end{array}$ & $\mathrm{s} / \mathrm{d}$ & $\mathrm{s} / \mathrm{d}$ & Presencia & $\mathrm{s} / \mathrm{d}$ & HTa1 & $\begin{array}{l}\text { Borrero \& } \\
\text { Massone, } 1994\end{array}$ \\
\hline 39 & Dos Herraduras 3 & $\begin{array}{l}\text { Magallanes, } \\
\text { Chile }\end{array}$ & 33 & $\mathrm{~s} / \mathrm{d}$ & 2 & $\mathrm{~s} / \mathrm{d}$ & HTa1 & Muñoz, 1997 \\
\hline 40 & Cueva del Milodón & $\begin{array}{l}\text { Magallanes, } \\
\text { Chile }\end{array}$ & $\mathrm{s} / \mathrm{d}$ & $\mathrm{s} / \mathrm{d}$ & Presencia & $\mathrm{s} / \mathrm{d}$ & HTa1 & Borrero, 1980 \\
\hline 9 & Alero Cicuta & $\begin{array}{l}\text { Neuquén, } \\
\text { Argentina }\end{array}$ & 13 & Ave & 1 & 1 & HTa2 & Silveira, 1999 \\
\hline 22 & Alero Las Guanacas & Aysén, Chile & 211 & Artiodáctilo & 38 & 6 & HTa2 & $\begin{array}{l}\text { Fuentes-Murchel \& } \\
\text { Mena, } 2010\end{array}$ \\
\hline 25 & Los Carneros & Aysén, Chile & 593 & Guanaco & 17 & $\mathrm{~s} / \mathrm{d}$ & HTa2 & $\begin{array}{l}\text { Mena \& López, } \\
2014\end{array}$ \\
\hline 30 & $\begin{array}{l}\text { Alero Gorra de } \\
\text { Vasco }\end{array}$ & $\begin{array}{l}\text { Santa Cruz, } \\
\text { Argentina }\end{array}$ & 269 & Guanaco & 3 & 1 & HTa2 & Rindel, 2008 \\
\hline 42 & Laguna Cóndor & $\begin{array}{l}\text { Santa Cruz, } \\
\text { Argentina }\end{array}$ & 330 & Guanaco & 4 & 1 & HTa2 & $\begin{array}{l}\text { Borrero \& } \\
\text { Borrazzo, } 2011\end{array}$ \\
\hline 11 & Valle Encantado 1 & $\begin{array}{l}\text { Río Negro, } \\
\text { Argentina }\end{array}$ & $\mathrm{s} / \mathrm{d}$ & Guanaco & Presencia & $\mathrm{s} / \mathrm{d}$ & Sin datar & $\begin{array}{l}\text { Hajduk \& } \\
\text { Albornoz, } 1999\end{array}$ \\
\hline 19 & $\begin{array}{l}\text { Cueva Baño Nuevo } \\
1\end{array}$ & Aysén, Chile & 137 & Guanaco & Presencia & 1 & $\begin{array}{c}3.000- \\
5.000 \\
\text { años AP }\end{array}$ & $\begin{array}{l}\text { Velásquez \& Mena, } \\
2006\end{array}$ \\
\hline 32 & $\begin{array}{l}\text { Cerro Casa de } \\
\text { Piedra Cueva } 7\end{array}$ & $\begin{array}{l}\text { Santa Cruz, } \\
\text { Argentina }\end{array}$ & 196 & Artiodáctilo & 4 & 1 & Sin datar & De Nigris, 2004b, \\
\hline 41 & Alero Quemado & $\begin{array}{l}\text { Magallanes, } \\
\text { Chile }\end{array}$ & 258 & Guanaco & 85 & 3 & $\begin{array}{c}\text { Post } \\
6.900 \\
\text { años AP }\end{array}$ & Sierpe et al. 2009 \\
\hline
\end{tabular}


un conjunto dominado por restos de guanaco. Se identificaron fragmentos del cráneo, la mandíbula y las extremidades, representación que, junto con las evidencias de procesamiento, fue interpretada como indicador del consumo intensivo de médula y grasas de huemul en una instancia de procesamiento inicial de las carcasas (Mena \& López, 2014).

El resto de los registros que poseen datos cuantitativos se caracteriza por los escasos especímenes de huemul (NISP $\leq 9$ ) a partir de los cuales es muy complejo recrear modalidades de aprovechamiento (Tabla 3). La excepción es el Alero Quemado (XII Región, Chile), que tiene un valor superior (NISP 85) a los observados en los registros de CCP y de Alero Las Guanacas (Tabla 3). Este conjunto también se destaca por presentar varias piezas con corte transversal regular, tanto de huemul como de guanaco. Mientras esta última especie fue recuperada a lo largo de toda la secuencia estratigráfica, los restos de huemul se concentran en una porción específica del depósito (Sierpe et al. 2009). Si bien dicha sección carece de fechados, la concentración de los restos sugiere que son el resultado de uno o varios eventos puntuales y relativamente cercanos en el tiempo, que pueden ser interpretados en el marco de una explotación ocasional de la especie. Los casos de Alero Gianella (XI Región de Aysén, Chile) y Laguna Cóndor (Santa Cruz, Argentina) podrían constituir otros ejemplos de este tipo de aprovechamiento, tratándose de sitios integrados a circuitos que articulaban bosque y estepa (Fuentes-Mucherl et al. 2012), incluso en tiempos históricos (L'Heureux, 2014).

\section{La explotación del huemul} en el bosque asociado al litoral maritimo

Esta unidad ambiental presenta 31 registros procedentes de 27 sitios, lo que la convierte en la unidad con mayor cantidad de sitios arqueológicos (Fig. 1). Estas evidencias se concentran en el suroeste del continente, fundamentalmente en la Región de Magallanes (Chile), en los mares de Skyring y Otway y en el estrecho de Magallanes (Tabla 4). El sitio Stuven 1 ( $47^{\circ} 44^{`} \mathrm{~S}$ ) es el único outlier en este patrón, reflejando posiblemente las diferente intensidad de trabajo arqueológico que exhibe la porción meridional versus el resto de los canales chilenos comprendidos entre el golfo de Penas y el estrecho de Magallanes. Los restos de huemul totalizan 615 especímenes y están concentrados en el bloque cronológico HTa2 (Fig. 4C).

Los restos de huemul se presentan en baja frecuencia desde los primeros registros disponibles (HM2) y en forma independiente al taxón dominante con que estén asociados, que en este tipo de ambiente suelen ser los otáridos, aves y peces. La excepción a esta tendencia es el sitio Río Caleta 2, ubicado en el mar de Otway y datado en 110 años AP, que ofrece un conjunto dominado por huemul aunque la muestra es muy pequeña (Tabla 4). Es posible que este conjunto refleje un evento puntual de caza de este cérvido, hecho sugerido por el carácter prácticamente monoespecífico de los restos recuperados, ya que de un total de 36 huesos, 28 fueron asignados a huemul, cinco a artiodáctilo, uno a pato vapor (Tachyres pteneres) y dos no pudieron ser determinados (San Román et al. 2002). Otro conjunto en el que el huemul supera el $10 \%$ del NISP general es el de Skyring 49a, que está dominado por restos de Artiodáctilo (NISP 133) y con una representación del huemul que alcanza a los 17 especímenes óseos (Tabla 4). En los restantes contextos la presencia de huemul tiende a ubicarse por debajo de los 10 especímenes identificados. Esto es así incluso en depósitos con gran volumen de restos óseos, en los cuales su representación puede ser mayor, pero siempre es baja. Por ejemplo, en Punta Baja 1, con más de 11.900 especímenes se recuperaron 454 restos de huemul, en Bahía Colorada, de los más de 6.000 especímenes uno solo es de huemul. En Punta Santa Ana, con más de 4.200 especímenes, se registraron 33 especímenes de huemul y en Pizzulic 2, con más de 3.500 especímenes, sólo cuatro restos (Tabla 4).

En sintesis, la gran cantidad de loci con restos de huemul sugiere que lo planteado por Legoupil (2000) para el seno de Skyring puede generalizarse a las zonas contiguas del extremo sur del continente: se trata de un recurso sistemáticamente cazado por grupos de economía marítima, que representó un aporte minoritario a la subsistencia de estas poblaciones, lo que coincide con el papel otorgado por San Román et al. (2002) a los artiodáctilos en general en el seno de Otway y canales 
Tabla 4. Registros con presencia de huemul ubicados en el ambiente de bosque asociado al litoral marítimo. Los registros están ordenados de los más antiguos a los más recientes y dentro de cada lapso, de norte a sur. Los que poseen menor precisión cronológica se listan al final de la tabla. $\mathrm{S} / \mathrm{d}=$ sin datos.

\begin{tabular}{|c|c|c|c|c|c|c|c|c|}
\hline $\begin{array}{l}\text { Referencia } \\
\text { en el mapa }\end{array}$ & Sitio & Ubicación & NISP & $\begin{array}{c}\text { Taxón } \\
\text { dominante }\end{array}$ & $\begin{array}{l}\text { NISP } \\
\text { Huemul }\end{array}$ & $\begin{array}{c}\text { MNI } \\
\text { Huemul }\end{array}$ & Período & Referencia bibliográfica \\
\hline 67 & Pizzulic 2 & Magallanes, Chile & 3.515 & Aves & 4 & $\mathrm{~s} / \mathrm{d}$ & HM2 & San Román, 2013 \\
\hline 69 & Bahía Colorada & Magallanes, Chile & 6.072 & Otáridos & 1 & 1 & HM2 & Legoupil, 1997 \\
\hline 56 & Skyring 26 & Magallanes, Chile & 4 & Aves & 2 & $\mathrm{~s} / \mathrm{d}$ & HTa1 & Legoupil, 2000 \\
\hline 48 & Stuven 1 & Aysén, Chile & 603 & Otáridos & 7 & $\mathrm{~s} / \mathrm{d}$ & HTa2 & Legoupil et al. 2007 \\
\hline 48 & Stuven 1 & Aysén, Chile & 992 & Peces & 9 & $\mathrm{~s} / \mathrm{d}$ & $\mathrm{HTa} 2$ & Legoupil et al. 2007 \\
\hline 48 & Stuven 1 & Aysén, Chile & 814 & Peces & 3 & $\mathrm{~s} / \mathrm{d}$ & HTa2 & Legoupil et al. 2007 \\
\hline 48 & Stuven 1 & Aysén, Chile & 329 & Peces & 1 & $\mathrm{~s} / \mathrm{d}$ & HTa2 & Legoupil et al. 2007 \\
\hline 48 & Stuven 1 & Aysén, Chile & 88 & Peces & 1 & $\mathrm{~s} / \mathrm{d}$ & $\mathrm{HTa} 2$ & Legoupil et al. 2007 \\
\hline 49 & Skyring 3 & Magallanes, Chile & 2.596 & Aves & 4 & $\mathrm{~s} / \mathrm{d}$ & $\mathrm{HTa} 2$ & Legoupil, 2000 \\
\hline 51 & Skyring 14 & Magallanes, Chile & 653 & Aves & 4 & $\mathrm{~s} / \mathrm{d}$ & $\mathrm{HTa} 2$ & Legoupil, 2000 \\
\hline 62 & Skyring $49 a$ & Magallanes, Chile & 133 & Artiodáctilo & 17 & $\mathrm{~s} / \mathrm{d}$ & $\mathrm{HTa} 2$ & Legoupil, 2000 \\
\hline 64 & Punta Eugenia 2 & Magallanes, Chile & 62 & Peces & 4 & $\mathrm{~s} / \mathrm{d}$ & $\mathrm{HTa} 2$ & San Román et al. 2002 \\
\hline 65 & Caleta Alonso 2 & Magallanes, Chile & 98 & Artiodáctilo & 1 & 1 & $\mathrm{HTa} 2$ & San Román et al. 2002 \\
\hline 68 & Pizzulic 4 & Magallanes, Chile & 270 & Aves & 1 & $\mathrm{~s} / \mathrm{d}$ & $\mathrm{HTa} 2$ & San Román, 2013 \\
\hline 70 & $\begin{array}{l}\text { Martín } \\
\text { Pescador } 2\end{array}$ & Magallanes, Chile & 100 & Peces & 6 & $\mathrm{~s} / \mathrm{d}$ & HTa2 & San Román et al. 2002 \\
\hline 71 & Río Caleta 2 & Magallanes, Chile & 34 & Huemul & 28 & $\mathrm{~s} / \mathrm{d}$ & $\mathrm{HTa} 2$ & San Román et al. 2002 \\
\hline 72 & Puesto La Sal & Magallanes, Chile & 1 & Huemul & 1 & 1 & $\mathrm{HTa} 2$ & San Román et al. 2002 \\
\hline 73 & Punta Baja 1 & Magallanes, Chile & 11.954 & Otáridos & 454 & 7 & HTa2 & Legoupil, 1989 \\
\hline 74 & $\begin{array}{l}\text { Punta Santa } \\
\text { Ana } 3\end{array}$ & Magallanes, Chile & 4.226 & Otáridos & 33 & $\mathrm{~s} / \mathrm{d}$ & HTa2 & Morello et al. 2012 \\
\hline 50 & Skyring 6 & Magallanes, Chile & 46 & Aves & 1 & 1 & $\begin{array}{l}\text { Posterior } \\
\text { al HM2 }\end{array}$ & Legoupil, 2000 \\
\hline 52 & Skyring 15 & Magallanes, Chile & 129 & Artiodáctilo & 1 & $\mathrm{~s} / \mathrm{d}$ & $\begin{array}{l}\text { Posterior } \\
\text { al HM2 }\end{array}$ & Legoupil, 2000 \\
\hline 53 & Skyring 16 & Magallanes, Chile & 129 & Aves & 4 & $\mathrm{~s} / \mathrm{d}$ & $\begin{array}{l}\text { Posterior } \\
\text { al HM2 }\end{array}$ & Legoupil, 2000 \\
\hline 54 & Skyring 24 & Magallanes, Chile & 212 & Aves & 8 & $\mathrm{~s} / \mathrm{d}$ & $\begin{array}{l}\text { Posterior } \\
\text { al HM2 }\end{array}$ & Legoupil, 2000 \\
\hline 55 & Skyring 25 & Magallanes, Chile & 80 & Aves & 2 & $\mathrm{~s} / \mathrm{d}$ & $\begin{array}{l}\text { Posterior } \\
\text { al HM2 }\end{array}$ & Legoupil, 2000 \\
\hline 57 & Skyring 28 & Magallanes, Chile & 4 & Artiodáctilo & 1 & $\mathrm{~s} / \mathrm{d}$ & $\begin{array}{l}\text { Posterior } \\
\text { al HM2 }\end{array}$ & Legoupil, 2000 \\
\hline 58 & Skyring 32 & Magallanes, Chile & 34 & Artiodáctilo & 2 & $\mathrm{~s} / \mathrm{d}$ & $\begin{array}{l}\text { Posterior } \\
\text { al HM2 }\end{array}$ & Legoupil, 2000 \\
\hline 59 & Skyring 34 & Magallanes, Chile & 64 & $\begin{array}{l}\text { Mamífero } \\
\text { marino }\end{array}$ & 2 & $\mathrm{~s} / \mathrm{d}$ & $\begin{array}{l}\text { Posterior } \\
\text { al HM2 }\end{array}$ & Legoupil, 2000 \\
\hline 60 & Skyring 35 & Magallanes, Chile & 7 & Artiodáctilo & 2 & $\mathrm{~s} / \mathrm{d}$ & $\begin{array}{l}\text { Posterior } \\
\text { al HM2 }\end{array}$ & Legoupil, 2000 \\
\hline 61 & Skyring 42 & Magallanes, Chile & 6 & Artiodáctilo & 1 & $\mathrm{~s} / \mathrm{d}$ & $\begin{array}{l}\text { Posterior } \\
\text { al HM2 }\end{array}$ & Legoupil, 2000 \\
\hline 63 & $\begin{array}{l}\text { Bahía Laredo - } \\
\text { Cabo Negro }\end{array}$ & Magallanes, Chile & $\mathrm{s} / \mathrm{d}$ & $\mathrm{s} / \mathrm{d}$ & Presencia & $\mathrm{s} / \mathrm{d}$ & $\begin{array}{l}\text { Posterior } \\
\text { al HM2 }\end{array}$ & Prieto, 1988 \\
\hline 66 & Caleta Eros 2 & Magallanes, Chile & 24 & Artiodáctilo & 10 & $\mathrm{~s} / \mathrm{d}$ & $\begin{array}{l}\text { Posterior } \\
\text { al HM2 }\end{array}$ & $\begin{array}{l}\text { San Román et al. } \\
2002\end{array}$ \\
\hline
\end{tabular}


adyacentes. Aun cuando algunas fuentes históricas, arqueológicas y etnográficas sugieren un papel más relevante para la especie (Bird, 1946; Emperaire, 1955; Fitz-Roy, 1839), el registro arqueológico dista de reflejar dicha importancia. En efecto, los restos de huemul contribuyen mínimamente a los conjuntos óseos, independientemente de que éstos sean numéricamente grandes o pequeños, y cuando realmente alcanzan una proporción importante serían el reflejo de un evento puntual de caza, tal como se propone para Río Caleta 2.

\section{La explotación del huemul en la estepa}

En este ambiente la evidencia de huemul se concentra entre los $46^{\circ} 56^{\prime} \mathrm{S}$ y los $52^{\circ} 52^{\prime} \mathrm{S}$. Hacia el este desde la franja de bosque, los sitios con evidencia de este cérvido $(\mathrm{N}=13)$ se ubican a partir de los $70^{\circ} 30^{\prime} \mathrm{O}$, y la localización más oriental corresponde al sitio P 35, en la desembocadura del río Santa Cruz (68 22' O, Tabla 5). Los más antiguos datan del HM1 pero son más numerosos en el HTa2 (Fig. 4D).

Los registros del primer lapso corresponden al Alero Destacamento Guardaparques (ADG) en Santa Cruz, Argentina y a la Cueva Fell (Magallanes, XII Región, Chile). En ADG (capa 7), sitio ubicado en el Parque Nacional Perito Moreno (PNPM), se hallaron cinco especímenes óseos de huemul -porciones distales de las extremidades (Rindel, 2008)- mientras que en la Cueva Fell (nivel 5), en el campo volcánico de Pali Aike, se recuperó un fragmento de maxilar con dos molares. En ambos casos los conjuntos óseos están dominados por restos de guanaco (Tabla 5). Con respecto al HM2, el único registro de huemul corresponde al nivel 10 del sitio Estancia Pueyrredón 2 (Santa Cruz, Argentina), del cual proviene un maleolar con huellas de corte (De Nigris \& Tecce, 2013, Tabla 5). En el período HTa1 los registros se circunscriben al nivel acerámico del sitio Alero Entrada Baker (Chile) y a la capa 5 de ADG (Tabla 5). Ambos conjuntos óseos están dominados por los restos de guanaco. En Alero Entrada Baker se menciona que los especímenes de huemul alcanzan el 6,7\% del NISP general del conjunto y corresponderían a un único individuo (Mena \& Jackson, 1991; Méndez \& Velásquez, 2005) mientras que en ADG se recuperaron fragmentos de cráneo, húmero, metapodio y una tercera falange (Rindel, 2008).

Hay seis registros correspondientes al HTa2. En el nivel Cerámico de Alero Entrada Baker, en el que el taxón dominante es el piche (Zaedyus pichiy) y el guanaco tiene un lugar secundario, se menciona la presencia de restos de un único individuo de huemul (Mena \& Jackson, 1991; Méndez \& Velásquez, 2005). En el sitio Río Verde 1 (XII Región) se recuperaron dos especímenes de huemul (Tabla 5). Ubicado en la costa oriental del seno de Skyring, este sitio fue caracterizado como un campamento de cazadoresrecolectores terrestres, en el que predominan los restos de guanaco (San Román et al. 2002). En el nivel 3 de Cerro Cuadrado 3 (Santa Cruz, Argentina) (Tabla 5) se recuperaron un fragmento de vértebra lumbar y un metatarso proximal con huellas de corte, en un conjunto dominado por los restos de guanaco (De Nigris \& Tecce, 2013). En el nivel RIII/5a de la Cueva Grande del Arroyo Feo (cuenca del río Pinturas, Santa Cruz, Argentina) se halló un fragmento de cráneo (escama occipital) clasificado como cérvido y considerado posiblemente de huemul, en un conjunto también dominado por restos de guanaco (Silveira, 1979). En el sitio ADO (PNPM) se recuperó un fragmento de metapodio distal con marcas de corte (Rindel, 2008). Este alero ha sido caracterizado como un sitio de actividades limitadas vinculadas a la caza de ungulados en la quebrada adyacente que da acceso a la meseta del Águila (Aschero et al. 19921993). Esta meseta es utilizada actualmente por los guanacos durante el verano $y$, de acuerdo con información brindada por pobladores, en el pasado solían verse huemules mezclados en las tropillas de guanacos (Goñi, 1988). Algunas escenas de caza registradas en la Cueva de la Manos, unos $150 \mathrm{~km}$ al noroeste del PNPM, muestran tropillas mixtas, en las que aparecen representados huemules entre varios guanacos (Aschero, 2012). La cercanía del ADO al bosque actual (aproximadamente $3 \mathrm{~km}$ ) permite comprender el uso de este ambiente por los huemules y su coexistencia con los guanacos. La presencia de un único resto de huemul en este conjunto podría deberse tanto a la caza en este contexto como al transporte de partes esqueletarias de animales capturados en el bosque. Finalmente, el último registro de huemul datado en el HTa2 es P 35, un conchero ubicado en la desembocadura 
Tabla 5. Registros con presencia de huemul ubicados en el ambiente de estepa. Los registros están ordenados de los más antiguos a los más recientes y dentro de cada lapso, de norte a sur. Los que poseen menor precisión cronológica se listan al final de la tabla. $\mathrm{S} / \mathrm{d}=$ sin datos.

\begin{tabular}{|c|c|c|c|c|c|c|c|c|}
\hline $\begin{array}{l}\text { Referencia } \\
\text { en el mapa }\end{array}$ & Sitio & Ubicación & NISP & $\begin{array}{c}\text { Taxón } \\
\text { dominante }\end{array}$ & $\begin{array}{l}\text { NISP } \\
\text { Huemul }\end{array}$ & $\begin{array}{l}\text { MNI } \\
\text { Huemul }\end{array}$ & Período & $\begin{array}{c}\text { Referencia } \\
\text { bibliográfica }\end{array}$ \\
\hline 34 & $\begin{array}{l}\text { Alero } \\
\text { Destacamento } \\
\text { Guardaparque }\end{array}$ & $\begin{array}{l}\text { Santa Cruz, } \\
\text { Argentina }\end{array}$ & 434 & Guanaco & 5 & 1 & HM1 & Rindel, 2008 \\
\hline 44 & Cueva Fell & $\begin{array}{l}\text { Magallanes, } \\
\text { Chile }\end{array}$ & 292 & Guanaco & 1 & 1 & HM1 & $\begin{array}{l}\text { Emperaire et al. } \\
1963\end{array}$ \\
\hline 28 & $\begin{array}{l}\text { Estancia } \\
\text { Pueyrredón } 2\end{array}$ & $\begin{array}{l}\text { Santa Cruz, } \\
\text { Argentina }\end{array}$ & 354 & Guanaco & 1 & 1 & HM2 & $\begin{array}{l}\text { De Nigris \& } \\
\text { Tecce, } 2013\end{array}$ \\
\hline 26 & $\begin{array}{l}\text { Alero Entrada } \\
\text { Baker }\end{array}$ & Aysén, Chile & 439 & Guanaco & Presencia & 1 & HTa1 & $\begin{array}{l}\text { Mena \& } \\
\text { Jackson, } 1991\end{array}$ \\
\hline 34 & $\begin{array}{l}\text { Alero } \\
\text { Destacamento } \\
\text { Guardaparque }\end{array}$ & $\begin{array}{l}\text { Santa Cruz, } \\
\text { Argentina }\end{array}$ & 424 & Guanaco & 4 & 1 & HTa1 & Rindel, 2008 \\
\hline 23 & $\begin{array}{l}\text { Cueva Grande del } \\
\text { Arroyo Feo }\end{array}$ & $\begin{array}{l}\text { Santa Cruz, } \\
\text { Argentina }\end{array}$ & 1.002 & Guanaco & 1 & 1 & HTa2 & Silveira, 1979 \\
\hline 26 & $\begin{array}{l}\text { Alero Entrada } \\
\text { Baker }\end{array}$ & Aysén, Chile & 880 & Piche & Presencia & 1 & HTa2 & $\begin{array}{l}\text { Mena \& } \\
\text { Jackson } 1991\end{array}$ \\
\hline 27 & Cerro Cuadrado 3 & $\begin{array}{l}\text { Santa Cruz, } \\
\text { Argentina }\end{array}$ & 216 & Guanaco & 2 & 1 & HTa2 & $\begin{array}{l}\text { De Nigris \& } \\
\text { Tecce, } 2013\end{array}$ \\
\hline 33 & $\begin{array}{l}\text { Alero Dirección } \\
\text { Obligatoria }\end{array}$ & $\begin{array}{l}\text { Santa Cruz, } \\
\text { Argentina }\end{array}$ & 550 & Guanaco & 1 & 1 & HTa2 & Rindel, 2008 \\
\hline 36 & P35 & $\begin{array}{l}\text { Santa Cruz, } \\
\text { Argentina }\end{array}$ & 1.704 & Otáridos & 1 & 1 & HTa2 & $\begin{array}{l}\text { Cruz et al. } \\
2010\end{array}$ \\
\hline 47 & Río Verde 1 & $\begin{array}{l}\text { Magallanes, } \\
\text { Chile }\end{array}$ & 627 & Artiodáctilo & 2 & $\mathrm{~s} / \mathrm{d}$ & HTa2 & $\begin{array}{l}\text { San Román et } \\
\text { al. } 2002\end{array}$ \\
\hline 29 & $\begin{array}{l}\text { Los Toldos Cueva } \\
3\end{array}$ & $\begin{array}{l}\text { Santa Cruz, } \\
\text { Argentina }\end{array}$ & 13 & Guanaco & 1 & 1 & $\begin{array}{c}\text { Posterior al } \\
\text { HM2 }\end{array}$ & $\begin{array}{l}\text { Cardich \& } \\
\text { Miotti, } 1983\end{array}$ \\
\hline 43 & Little Hill & $\begin{array}{l}\text { Santa Cruz, } \\
\text { Argentina }\end{array}$ & 1 & $\begin{array}{l}\text { No hay } \\
\text { huesos }\end{array}$ & 1 & 1 & Sin datar & $\begin{array}{l}\text { Carballo Marina } \\
\text { et al. } 2008\end{array}$ \\
\hline 44 & Cueva Fell & $\begin{array}{l}\text { Magallanes, } \\
\text { Chile }\end{array}$ & 188 & Guanaco & 2 & 1 & Sin datar & $\begin{array}{l}\text { Emperaire et al. } \\
1963\end{array}$ \\
\hline 45 & San Gregorio 10 & $\begin{array}{l}\text { Magallanes, } \\
\text { Chile }\end{array}$ & $\mathrm{s} / \mathrm{d}$ & $\mathrm{s} / \mathrm{d}$ & 1 & 1 & Sin datar & Massone, 1984 \\
\hline 46 & Isla Isabel & $\begin{array}{l}\text { Magallanes, } \\
\text { Chile }\end{array}$ & $\mathrm{s} / \mathrm{d}$ & $\mathrm{s} / \mathrm{d}$ & Presencia & $\mathrm{s} / \mathrm{d}$ & Sin datar & $\begin{array}{l}\text { Borrero \& } \\
\text { Borrazo, } 2011\end{array}$ \\
\hline
\end{tabular}

del río Santa Cruz (Cruz et al. 2010), en el que predominan los pinnípedos. En este caso se recuperó un asta con modificaciones culturales, de la que se obtuvo una fecha-taxón de $1.150 \pm 30$ años AP. Su señal isotópica $\left(\delta^{15} \mathrm{~N}+0,34\right)$ es similar a la registrada en restos óseos de huemules modernos procedentes de zonas de bosque o de ecotono bosque-estepa (véase Tessone et al. 2014), lo cual permite inferir que fue transportada, posiblemente debido a las cualidades del asta para la confección de instrumentos.

Sin datación, pero con una asignación post 
HM2, en la Cueva 3 de Los Toldos (Santa Cruz, Argentina) se recuperó un espécimen determinado como Cervidae y asignado a huemul (Cardich \& Miotti, 1983). Otros registros de la especie sin asignación temporal son los de los sitios Isla Isabel (Borrero \& Borrazzo, 2011) y San Gregorio 10 (Massone, 1984), ambos en el estrecho de Magallanes, y la laguna Little Hill, en la cuenca superior del río Gallegos (Santa Cruz, Argentina; Carballo Marina et al. 2008). Estos tres registros corresponden a astas o fragmentos de astas, por lo que, como en el caso de P 35, consideramos que fueron transportadas desde áreas de bosque. Por último, en un nivel sin fechados de Cueva Fell se recuperó un maxilar con molares de huemul.

La baja representación del huemul en la estepa no respondería a una preservación diferencial dado que sus huesos poseen características -tamaño, morfología y densidad mineral- similares a los de guanaco especie representada por cientos de especímenes en casi todos los sitios arqueológicos de la estepa patagónica. Por lo tanto, la ausencia de restos de huemul en los depósitos arqueológicos de este ambiente puede atribuirse a que el huemul no ocupó este bioma en el pasado. Así, las evidencias de huemul halladas en los sitios emplazados en la estepa dan cuenta de diferentes situaciones que, en primera instancia, parecen estar condicionadas por la distancia entre el sitio de recuperación y el ambiente de bosque o el ecotono bosque-estepa. De los 13 sitios, siete se ubican a un máximo de $20 \mathrm{~km}$ del ecotono bosque-estepa actual (aunque la mayoría está a menos de $10 \mathrm{~km}$ ). En ellos la presencia de restos de huemul fue explicada por (a) el desplazamiento de los cazadores que incursionan en el bosque (De Nigris \& Tecce, 2013; Mena \& Jackson, 1991; Rindel, 2008) o por (b) el movimiento estacional de los huemules hacia sectores esteparios particulares, como las pasturas de la meseta del Águila (Goñi, 1988; Rindel, 2008). Una tercera situación se relaciona con el transporte de astas para su empleo en manufacturas, observada en P35, sitio ubicado a $315 \mathrm{~km}$ del bosque actual. Las astas halladas en San Gregorio 10, Isla Isabel y Little Hill -a ca. 60, 20 y $28 \mathrm{~km}$ del bosque actual, respectivamentepodrían interpretarse como resultado de un comportamiento similar. En forma alternativa, el asta de Little Hill podría corresponder a un volteo relacionado con la mayor movilidad de los huemules ante el recrudecimiento del clima invernal (Charlin et al. 2011). Por último, la interpretación de los restos recuperados en los sitios Cueva Grande del Arroyo Feo, Los Toldos 3 y Cueva Fell, emplazados a más de $100 \mathrm{~km}$ del bosque actual, también podrían entenderse por el transporte. La determinación de la señal isotópica del carbono y especialmente del nitrógeno permitirá evaluar esta hipótesis.

\section{DISCUSIÓN Y CONCLUSIONES}

El análisis desarrollado sugiere que, aun partiendo de un cuerpo de datos caracterizado por muestras de tamaño reducido y por grandes disparidades en los detalles con que los materiales han sido publicados -que a la vez reflejan distintos momentos de las investigaciones zooarqueológicases posible evaluar las condiciones bajo las cuales se establecieron las relaciones interespecíficas entre los seres humanos y el huemul en Patagonia. La escala regional permite superar estas debilidades al identificar tendencias al nivel de las unidades ambientales consideradas, las que son interpretables en términos de la importancia relativa de este cérvido respecto de otros recursos con un registro más conspicuo. La revisión precedente reafirma lo planteado en una primera aproximación a este tema (Fernández et al. 2015): durante el Holoceno el aprovechamiento del huemul fue siempre oportunista, en el sentido empleado por Jaksic (1989). Su definición de oportunismo, a diferencia del empleo que habitualmente se hace de este concepto en arqueología, propone que una especie es cazada en la misma proporción en la que está disponible a lo largo del tiempo y del espacio. En el caso del huemul, esto se evidencia en la concentración de registros $(85 \%$, Fig. 3) que presentan las unidades ambientales bosque andino ( $\mathrm{N}=24)$, ecotono bosque-estepa $(\mathrm{N}=42)$ y bosque asociado al litoral marino ( $\mathrm{N}=30)$, las que coinciden con el hábitat natural de la especie (Vila et al. 2010).

Del análisis también pudimos desprender que la explotación de este cérvido no sólo estuvo de acuerdo con su abundancia natural sino también con la disponibilidad y abundancia de las presas alternativas. Los datos provenientes de los espacios 
"transicionales" (ecotono bosque-estepa) y del "límite" del bosque (por ejemplo el asociado al litoral marino) muestran que el huemul nunca constituyó la primera opción en estas unidades ambientales. Por el contrario, su lugar en la subsistencia fue siempre marginal o complementario. Ejemplo de este punto son los registros de CCP5 y CCP7, los que evidencian que a lo largo de 7.200 años el guanaco fue la presa principal. Dado que se trata de ungulados con rendimiento similar es posible interpretar que la mayor densidad poblacional del guanaco fue el factor determinante para privilegiar a este camélido por sobre el huemul. Por otra parte, los datos del bosque muestran la selección recurrente del huemul y, si bien son pequeños en términos de NISP, los conjuntos se encuentran dominados por este cérvido. Esto se explica porque se trata de la única presa de tamaño mediano-grande disponible en el interior del bosque. El contraste entre el bosque y las unidades ambientales de su "periferia" indica que la importancia del huemul en la subsistencia depende de la estructura de recursos de cada ambiente. De lo anterior deducimos que la dominancia del huemul en los conjuntos del bosque informa sobre la selección humana de este espacio, más que acerca de la preferencia de una presa específica. Puede verse entonces que la lectura regional de los datos también es útil para analizar el uso humano de los diferentes ambientes de Patagonia, particularmente el bosque, y calibrar la importancia relativa que algunos recursos particulares pudieron tener al momento de la incorporación de un ambiente determinado a la geografía cultural de los grupos cazadores-recolectores.

Asimismo, el análisis de los registros con información sobre la explotación del huemul nos permitió aislar diferentes situaciones de aprovechamiento de la especie, que incluyen el empleo de astas para la confección de instrumentos (por ejemplo, P35), la selección de espacios óptimos para la caza debido a la concentración de presas (por ejemplo, Alero Fontana), eventos puntuales de obtención (posiblemente, Río Caleta 2 y Alero Quemado) y quizá la explotación de tropillas mixtas de guanacos y huemules (como evidencia el sitio ADO). En ese sentido, las representaciones rupestres del área del río Pinturas (Santa Cruz, Argentina), que muestran tropas de guanacos y huemules en situación de caza, podrían interpretarse a la luz de esta hipótesis. Si bien se ha planteado que las escenas no estarían reflejando una asociación en tiempo real de ambas especies (Aschero, 2012), lo propuesto para el sitio ADO abre la posibilidad de que las pinturas estén plasmando eventos puntuales en que dicha sincronía tuvo lugar. Que ambos ungulados compartan el mismo espacio de representación es coherente con las interpretaciones que pueden efectuarse desde el registro arqueofaunístico, es decir que los huemules son aprovechados si están disponibles en el marco de estrategias destinadas a explotar un recurso principal, que es el guanaco. En efecto, las proporciones en que guanacos y huemules están representados en las pinturas reproducen el predominio de los primeros observado en los conjuntos óseos del ecotono bosque-estepa y de la estepa del NO de Santa Cruz. La representación de machos y hembras de huemul intercalados con guanacos (Grupo estilístico A, estilo A3 [Series rojas], en Aschero, 2012) también podría reflejar la estacionalidad de estas tropillas si, como se menciona para el caso de la meseta del Águila, la mezcla de especies tenía lugar durante el verano, y coincidía con la época de parición local de ambos ungulados (Goñi, 1988).

En síntesis, el papel desempeñado por el huemul en la subsistencia de las sociedades de cazadores-recolectores que ocuparon Patagonia a lo largo del Holoceno estuvo ligado a la historia de uso de los diferentes espacios patagónicos. Aun cuando es uno de los pocos vertebrados de tamaño mediano-grande nativo de la región, esto no lo transformó en un recurso importante, excepto en situaciones en las que no había presas de alto rinde alternativas (como guanacos, otáridos y ciertas aves). Cuando las había, estas otras presas fueron preferidas, debido a diversos factores, entre los que se destacan la estructura de los recursos (en particular su densidad y predictibilidad) y el tamaño de los grupos humanos, que en términos generales no habrían alcanzado la magnitud necesaria como para presionar de manera significativa sobre las poblaciones de huemul durante el Holoceno.

\section{AGRADECIMIENTOS}

Flavia Morello, Manuel San Román, Luís 
Borrero y Fabiana Martin aportaron datos y precisiones sobre los sitios estudiados por ellos. Manuel San Román nos facilitó gentilmente la imagen del ecotono bosque-litoral marítimo. Agradecemos los comentarios efectuados por nuestros colegas María Gutiérrez, Sabrina Leonardt, Flavia Carballo Marina, Matías Medina y de dos evaluadores anónimos que ayudaron a mejorar el trabajo y a Ana Forlano, que contribuyó con el diseño del mapa y el armado de las fotografías. Las investigaciones fueron financiadas por el CONICET, la ANPCyT, la Universidad de Buenos Aires, la Universidad Nacional de la Patagonia Austral y la Universidad Nacional de Córdoba.

\section{BIBLOGRAFÍA}

Arrigoni, G., \& Fernández, P. M. (2004). Los restos óseos del Alero del Sendero de Interpretación: integridad, resolución y aprovechamiento de los recursos faunísticos del bosque. En M. T. Civalero, P. M. Fernández, \& A. G. Guráieb (Eds.), Contra viento y marea. Arqueología de Patagonia (pp. 403-415). Buenos Aires: Sociedad Argentina de Antropología-Instituto Nacional de Antropología y Pensamiento Latinoamericano.

Aschero, C. A. (2012). Las escenas de caza en Cueva de las Manos: Una perspectiva regional (Santa Cruz, Argentina). En J. Clottes (Ed.), L'art pléistocène dans le monde/Pleistocene art of the world/Arte Pleistoceno en el mundo Actes du Congrès IFRAO (pp. 807-823). Tarascon-sur-Ariège: Bulletin de la Société Préhistorique Ariège-Pyrénées LXV-LXVI.

Aschero, C. A., Bellelli, C. T., \& Goñi, R. A. (1992-1993). Avances en las investigaciones arqueológicas del Parque Nacional Perito Moreno (Provincia de Santa Cruz, Patagonia Argentina). Cuadernos del Instituto Nacional de Antropología y Pensamiento Latinoamericano, 14, 143-170.

Belardi, J. B., \& Gómez-Otero, J. (1998). Anatomía económica del huemul (Hippocamelus bisulcus): una contribución a la interpretación de las evidencias arqueológicas de su aprovechamiento en Patagonia. Anales del Instituto de la Patagonia, Serie Ciencias Humanas, 26, 195207.

Bird, J. (1946). The Alacaluf. En J. H. Steward (Ed.), Handbook of South American Indians 1 (pp. 55-79). Washington DC: Smithsonian Institution.

Borrero, L. A. (1980). Arqueología del Seno de la Última Esperanza (Magallanes, Chile). Actas del Congreso
Nacional de Arqueología Uruguaya (pp. 11-16). Colonia del Sacramento.

Borrero, L. A. (1999). The Prehistoric Exploration and Colonization of Fuego-Patagonia. Journal of World Prehistory, 13(3), 321-355.

Borrero, L. A. (2013). Estrategias de caza en Fuego-Patagonia. Comechingonia. Revista de Arqueología, 17(1), 1126.

Borrero, L. A., \& Borrazzo, K. (2011). La geografía cultural del sudoeste de Patagonia Continental. En L. A. Borrero \& K. Borrazzo (Eds.), Bosques, montañas y cazadores. Investigaciones arqueológicas en Patagonia Meridional (pp. 7-36). Buenos Aires: CONICETIMHICIHU.

Borrero, L. A., \& Massone, M. (1994). Arqueología de los aleros de Dos Herraduras, Última Esperanza, Chile. Revista del Museo de Historia Natural de San Rafael, 14(1/4), 288-289.

Carballo Marina, F., Manzi, L. M., Campán, P. A., Belardi, J. B., Tiberi, P., Manero, A., \& Sáenz, J. L. (2008). Distribución del registro arqueológico en la cuenca del río Gallegos (Provincia de Santa Cruz): línea de base y aporte a la preservación del patrimonio. En L. A. Borrero, \& N. V. Franco (Eds.), Arqueología del Extremos Sur del Continente Americano. Resultados de nuevos proyectos (pp. 175-225). Buenos Aires: CONICET.

Carballido Calatayud, M., \& Fernández, P. M. (2013). La caza de ungulados en el bosque de Patagonia. Aportes desde la localidad de Cholila (Chubut, Argentina). Relaciones de la Sociedad Argentina de Antropología, 38(1), 5982.

Cardich, A., \& Miotti, L. (1983). Recursos faunísticos en la economía de los cazadores-recolectores de Los Toldos (provincia de Santa Cruz). Relaciones de la Sociedad Argentina de Antropología, 15, 145-157.

Ceballos, R. (1982). El sitio Cuyín Manzano. Serie de estudios y documentos, 9, 1-66.

Cordero, J. A. (2010). Explotación animal en el Holoceno del noroeste de la Patagonia argentina. Cambios climáticos y transformaciones del comportamiento humano: una primera aproximación. (Tesis inédita de doctorado). Facultad de Filosofía y Letras, Universidad de Buenos Aires. Buenos Aires.

Charlin, J, Borrero, L. A., \& Pallo, C. (2011). Ocupaciones humanas en el área Noroccidental del río Gallegos (Prov. de Santa Cruz, Argentina). En L. A. Borrero, \& K. Borrazzo (Eds.), Bosques, Montañas y Cazadores. Investigaciones arqueológicas en Patagonia 
Meridional (pp. 179-210). Buenos Aires: CONICETIMHICIHU, Impresiones Dunken.

Cruz, I., Muñoz, A. S., \& Caracotche, M. S. (2010). Un artefacto en asta de huemul (Hippocamelus bisulcus) en depósitos arqueológicos costeros. Implicaciones para la movilidad humana y la distribución de la especie. Magallania, 38(1), 289-296.

De Nigris, M. E. (2004a). Guanaco and huemul in Patagonian hunter-gatherers diet. En G. L. Mengoni Goñalons (Ed.), Zooarchaeology of South America (pp. 11-37). Oxford: British Archaeological Reports, International Series 1298. Archaeopress.

De Nigris, M. E. (2004b). El consumo en grupos cazadores recolectores. Un ejemplo zooarqueológico de Patagonia Meridional. Buenos Aires: Sociedad Argentina de Antropología.

De Nigris, M. E. (2007). Nuevos datos, viejas colecciones: los conjuntos óseos de Cerro Casa de Piedra Cueva 5 (Parque Nacional Perito Moreno, Santa Cruz). Intersecciones en Antropología, 8, 253-264.

De Nigris, M. E., Lacrouts, A., \& Tecce, S. (2010). Nuevos datos zooarqueológicos de las ocupaciones tempranas de Cerro Casa de Piedra Cueva 7 (Santa Cruz, Argentina). En M. A. Gutiérrez, M. De Nigris, P. M. Fernández, M. Giardina, A. F. Gil, A. Izeta, G. Neme, \& H. D. Yacobaccio (Eds.), Zooarqueología a principios del siglo XXI: aportes teóricos, metodológicos y casos de estudio (pp. 209-217). Buenos Aires: Ediciones del Espinillo.

De Nigris, M., \& Tecce, S. (2013). Estudios zooarqueológicos del lago Pueyrredón-Cochrane (Santa Cruz, Argentina). En A. F. Zangrando, R. Barberena, A. Gil, G. Neme, M. Giardina, L. Luna, C. Otaola, S. Paulides, L. Salgán, \& A. Tivoli (Eds.), Tendencias teórico-metodológicas y casos de estudio en la arqueología de la Patagonia (pp. 335-342). San Rafael: Museo de Historia Natural de San Rafael.

de Porras, M. E., Maldonado, A., Abarzúa, A. M., Cárdenas, M. L., Francois, J. P., Martel-Cea, A., Stern, C. R., Méndez, C., \& Reyes, O. (2012). Postglacial vegetation, fire and climate dynamics at Central Chilean Patagonia (Lake Shaman, $44^{\circ}$ S). Quaternary Science Review, $50,71-85$.

Emperaire, J. 1955. Les Nomades de la Mer. Paris: Gallimard. Emperaire, J., Laming-Emperaire A., \& Reichlen, H. (1963). La grotte Fell et autres sites de la région volcanique de la Patagonie chilienne. Journal de la Société des Américanistes, N.S. 52, 167-254.

Fernández, P. M. (2000). Rendido a tus pies: acerca de la composición anatómica de los conjuntos arqueofaunísticos con restos de Rheiformes de Pampa y Patagonia. En Desde el país de los gigantes. Perspectivas arqueológicas en Patagonia, Tomo II (pp. 573-586). Río Gallegos: Universidad Nacional de la Patagonia Austral.

Fernández, P. M. (2008). Taphonomy and zooarchaeology in the Neotropics: A view from northwestern Patagonian forest and steppe. Quaternary Internacional, 180, 6374. doi:10.1016/j.quaint.2007.08.012

Fernández, P. M. (2010). Cazadores y presas. 3500 años de interacción entre seres humanos y animales en el Noroeste de Chubut. Buenos Aires: Fundación de Historia Natural Félix de Azara.

Fernández, P. M. (2011). Análisis zooarqueológico de los materiales óseos recuperados en el sitio Alero del Shaman (Parque Nacional Los Alerces). Informe técnico inédito. Bariloche: Delegación Regional Patagonia, Administración de Parques Nacionales.

Fernández, P. M., \& Andrade, A. (2011). Tafonomía y procesos de formación del registro arqueológico en el bosque andino norpatagónico: el caso del sitio Paredón Lanfré (provincia de Río Negro). Trabajo presentado en el II Congreso Nacional de Zooarqueología Argentina, Olavarría.

Fernández, P. M., \& Carballido Calatayud, M. (2015). Armas y presas. Técnicas de caza en el interior del bosque patagónico. Relaciones de la Sociedad Argentina de Antropología, 40(1), 279-301.

Fernández, P. M., Cruz, I., Belardi, J. B., De Nigris, M., \& Muñoz, A. S. (2015). Human predation and natural history of huemul (CERVIDAE; Hippocamelus bisulcus Molina) in Patagonia: A zooarchaeological Analysis. Journal of Ethnobiology, 35(3), 472-498.

Fernández, P. M., \& Forlano, A. I. (2009). Tafonomía, arqueología y conservación de especies silvestres: el caso de los huemules (Hippocamelus bisulcus) de lago la Plata (Chubut). En M. Salemme, F. Santiago, M. Álvarez, E. Piana, M. Vázquez, \& E. Mansur (Eds.), Arqueología de la Patagonia: una mirada desde el último confin (pp. 743-758). Ushuaia: Editorial Utopías.

Fernández, P. M. \& Tessone, A. (2014). Modos de ocupación del bosque patagónico de la vertiente oriental de los Andes. Aportes desde la ecología isotópica. Revista Chilena de Antropología, 30(2), 83-89.

Fitz-Roy, R. (1839). Narrative of the surveying voyages of His Majesty's Ships Adventure and Beagle between the years 1826 and 1836, describing their examination 
of the southern shores of South America, and the Beagle's circumnavigation of the globe. Appendix to Volume II. London: Henry Colburn. Recuperado de http://darwin-online.org.uk/content/ frameset?itemID=F10.2a\&viewtype=text\&pageseq=1.

Fuentes-Mucherl, F., \& Mena, F. (2010). Estacionalidad y movilidad en cazadores-recolectores: el caso de Cueva Las Guanacas (valle del río Ibáñez, Aisén, Chile). Revista Werkén, 13, 359-370.

Fuentes-Mucherl, F., Mena, F., Blanco, J., \& Contreras, C. (2012). Excavaciones en Alero Gianella, curso medio del valle de Chacabuco (Andes Centro Patagónicos). Magallania, 40(2), 259-265.

Goñi, R. A. (1988). Arqueología de momentos tardíos en el Parque Nacional Perito Moreno (Santa Cruz, Argentina). Precirculados del IX Congreso Nacional de Arqueología Argentina (pp. 140-151). Buenos Aires: Universidad de Buenos Aires.

Hajduk, A., \& Albornoz, A. (1999). El sitio Valle Encantado 1. Su vinculación con otros sitios: un esbozo de la problemática local diversa del Nahuel Huapi. En Soplando en el Viento. Actas de las Terceras Jornadas de Arqueología de la Patagonia (pp. 371391). Neuquén-Buenos Aires: Universidad Nacional del Comahue e Instituto Nacional de Antropología y Pensamiento Latinoamericana.

Hajduk A., Albornoz, A., \& Lezcano, M. J. (2004). El Mylodon en el patio de atrás. Informe preliminar sobre los trabajos en el sitio El Trébol, ejido urbano de San Carlos de Bariloche, provincia de Río Negro. En M. T. Civalero, P. M. Fernández, \& A. G. Guráieb (Eds.), Contra viento y marea. Arqueología de Patagonia (pp. 715-731). Buenos Aires: Instituto Nacional de Antropología y Pensamiento LatinoamericanoSociedad Argentina de Antropología.

Hajduk, A., Albornoz, A., Lezcano, M., \& Arias Cabral, P. (2012). The first occupations of the El Trébol site during the Pleistocene-Holocene transition (Nahuel Huapi lake, Patagonia, Argentina). En L. Miotti, M. Salemme, N. Flegenheimer, \& T. Goebel (Eds.), Southbound late Pleistocene peopling of Latin America. Current Research in the Pleistocene, Special Edition (pp. 117120). Texas: Texas A\&M University.

Iglesias, V., Whitlock, C., Bianchi, M. M., Villarosa G., \& Outes, V. (2012). Holocene climate variability and environmental history at the Patagonian forest/ steppe ecotone: Lago Mosquito (42²9'37.89'’S, 71'24'14.57' 'W) and Laguna del Cóndor (42²0'47.22's, 71¹7'07.62'”W). The Holocene,
22, 1297-1307.

Jaksic, F. M. (1989). Opportunism vs. selectivity among carnivorous predators that eat mammalian prey: a statistical test of hypotheses. Oikos, 56, 427-430.

Legoupil, D. (1989). Ethno-archéologie dans les archipels de Patagonie: les nomades marins de Punta Baja. Mémoire ${ }^{\circ}$ 84. Paris: Ministère des Affaires Etrangères, Editions Recherche sur les Civilisations.

Legoupil, D. (1997). Bahia Colorada (ile d'Englefield). Les premiers chasseurs de mammifères marins de Patagonie australe. Paris: Ministère des Affaires Étrangères, Éditions Recherche sur les Civilisations.

Legoupil, D. (2000). El sistema socioeconómico de los nómades del mar de Skyring (Archipiélago de Patagonia). Anales del Instituto de la Patagonia, Serie Ciencias Humanas, 28, 81-119.

Legoupil, D., Bearez, P., Lepetz, S., San Roman, M., \& Salas, K. (2007). De la pesca a la caza: evolución económica del sitio Stuven 1, al sur del Golfo de Penas. En F. Morello, M. Martinic, A. Prieto, \& G. Bahamonde (Eds.), Arqueología de Fuego-Patagonia. Levantando piedras, desenterrando huesos... y develando arcanos (pp. 279-294). Punta Arenas: Ediciones CEQUA.

Lezcano, M. J., Hajduk, A., \& Albornoz, A. M. (2010). El menú a la carta en el bosque ¿entrada o plato fuerte?: una perspectiva comparada desde la zooarqueología del sitio El Trébol (lago Nahuel Huapi, Pcia. de Río Negro). En M. A. Gutiérrez, M. De Nigris, P. M. Fernández, M. Giardina, A. F. Gil, A. Izeta, G. Neme \& H. D. Yacobaccio (Eds.), Zooarqueología a principios del siglo XXI: aportes teóricos, metodológicos y casos de estudio (pp. 243-257). Buenos Aires: Ediciones del Espinillo.

L'Heureux, L. (2014). El uso de la fauna en la laguna Cóndor, provincia de Santa Cruz, Argentina. Trabajo presentado en las X Jornadas de Arqueología de la Patagonia, Coyhaique.

Lyman, R. L. (2008). Quantitative paleozoology. New York: Cambridge University Press.

Markgraf, V., Whitlock, C., \& Haberle, S. (2007). Vegetation and fire history during the last 18,000 cal yr B.P. in Southern Patagonia: Mallín Pollux, Coyhaique, Province Aisén (4541'30" S, 7150'30” W, 640 m elevation). Palaeogeography, Palaeoclimatology, Palaeoecology, 254, 492-507.

Massone, M. (1984). Paradero tehuelches y prototehuelches en la costa del Estrecho de Magallanes (una aproximación teórica y metodológica). Anales del Instituto de la Patagonia, Serie Ciencias Sociales, 15, 27-42. 
Mena, F. (1992). Mandíbulas y maxilares: un primer acercamiento a los conjuntos arqueofaunísticos del Alero Fontana (RI-22; XI Región). Boletín del Museo Nacional de Historia Natural de Chile, 43, 179-191.

Mena, F., \& Jackson, D. (1991). Tecnología y subsistencia en Alero Entrada Baker, Región de Aysén, Chile. Anales del Instituto de la Patagonia, Serie Ciencias Sociales, 20, 169-203.

Mena, F., \& López, P. (2014). Los restos faunísticos de los niveles superiores de cueva Los Carneros (Alto Chacabuco, XI Región, Chile). Revista Chilena de Antropología, 30(2), 121-128.

Mena, F., Velásquez, Trejo, V., \& Torres-Mura, J. C. (2004). Aproximaciones zooarqueológicas al pasado de Aysén continental (Patagonia Central Chilena). En G. L. Mengoni Goñalons (Ed.), Zooarchaeology of South America, (pp. 99-120). Oxford: British Archaeological Reports, International Series 1298, Archaeopress.

Méndez, C., R. Barberena, Reyes, O., \& Nuevo Delaunay, A. (2014). Isotopic Ecology and Human Diets in the Forest Steppe Ecotone, Aisén Region, CentralWestern Patagonia, Chile. International Journal of Osteoarchaeology, 24(2), 187-201.

Méndez, C., \& Velásquez, H. (2005). Tecnología y subsistencia en Alero Entrada Baker: una revisión a la luz de nuevos antecedentes. Actas del XVI Congreso Nacional de Arqueología Chilena, (pp. 593-602). Concepción: Ediciones Escaparate.

Morello, F., Torres, J., Martínez, I., Rodríguez, K., Arroyo-Kalin, M., French, C., Sierpe, V., \& San Román, M. (2012). Arqueología de la Punta Santa Ana: Reconstrucción de secuencias de ocupación de cazadores-recolectores marinos del estrecho de Magallanes, Patagonia Austral, Chile. Magallania, 40(2), 129-149.

Muñoz, A. S. (1997). Explotación y procesamiento de ungulados en Patagonia meridional y Tierra del Fuego. Anales del Instituto de la Patagonia, Serie Ciencias Sociales, 25, 201-222.

Muñoz, A. S. (2011). Pinniped zooarchaeological studies in Southern Patagonia: current issues and future research agenda. En N. F. Bicho, J.A. Haws, \& L.G. Davis (Eds.), Trekking the shore: changing coastlines and the antiquity of coastal settlement, (pp. 305-332). New York: Springer.

Pérez, A. E., \& Batres, D. A. (2008). Los otros cazadores. Explotación de cérvidos en la localidad arqueológica Meliquina, Parque Nacional Lanín, República Argentina. En J. C. Díez (Ed.), Zooarqueología hoy. Encuentros Hispano-Argentinos (pp. 89-107).
Burgos: Universidad de Burgos.

Pérez de Micou, C., Castro Esnal, A., Casanueva, M. L., \& Sacchi, M. (2014). Estudios arqueológicos en Aldea Beleiro, SO del Chubut, Argentina. Póster presentado en las IX Jornadas de Arqueología de la Patagonia. Recuperado de http://www.saantropologia.com.ar/ wp-content/uploads/2014/12/PosterCoyaique.pdf

Perrota, E., \& Pereda, I. (1987). Nuevos datos sobre el alero IV del Tromen (Dto. Picunches, Prov. de Neuquén). En Comunicaciones. Primeras Jornadas de Arqueología de la Patagonia, Serie Humanidades 2 (pp. 249-258). Rawson: Gobierno de la provincia del Chubut.

Podestá, M. M., Bellelli, C., Fernández, P., Scheinsohn, V., Carballido Calatayud, M., Forlano,A., Marchione, P., Tropea, E., Vasini, A., Alberti, J., Gallo, M., \& Moscovici Vernieri, G. (2007). Arqueología del valle del río Epuyén (El Hoyo, Chubut, Patagonia Argentina). En F. Morello, M. Martinic, A. Prieto, \& G. Bahamonde (Eds.), Arqueología de Fuego-Patagonia. Levantando piedras, desenterrando huesos...y develando arcanos (pp. 427-442). Punta Arenas: Ediciones CEQUA.

Prieto, A. (1988). Cazadores-recolectores del istmo de Brunswick. Anales del Instituto de la Patagonia, Serie Ciencias Sociales, 18, 113-131.

Redford, K. H., \& Eisenberg, J. F. (1992). Mammals of the Neotropics. The Southern Cone, Volume 2, Chile, Argentina, Uruguay, Paraguay Chicago y Londres: The University of Chicago Press.

Reigadas, M. C. (2005). Cazadores del Holoceno y los recursos faunísticos. Estudio de fibras animales de Cerro Casa de Piedra -CCP5 y CCP7- (Santa Cruz). Relaciones Sociedad Argentina de Antropología, 30, 235-243.

Rindel, D. (2008). Arqueología de Momentos Tardios en el Noroeste de la Provincia de Santa Cruz (Argentina): una Perspectiva Faunística. Tesis inédita de Doctorado. Facultad de Filosofía y Letras, Universidad de Buenos Aires. Buenos Aires

Salemme, M., \& Frontini, R. (2011). The exploitation of RHEIDAE in Pampa and Patagonia (Argentina) as recorded by chroniclers, naturalists and voyagers. Journal of Anthropological Archaeology, 30, 473483.

San Román Bontes, M. (2013). Sitios arqueológicos de la Isla Englefield, mar de Otway: nuevas evidencias de discontinuidad cultural en el proceso de poblamiento marítimo de Patagonia Meridional. En A. F. Zangrando, R. Barberena, A. Gil,G. Neme, M. Giardina, L. Luna, C. Otaola, S. Paulides, L. Salgán, \& A. Tivoli (Eds.), Tendencias teórico metodológicas y casos de estudio 
en la arqueología patagónica (pp. 523-534). San Rafael: Museo de Historia Natural de San Rafael.

San Román, M., Morello, F., \& Prieto, A. (2002). Nuevos antecedentes sobre la explotación de recursos faunísticos en el Mar de Otway y canales adyacentes. Anales del Instituto de la Patagonia, Serie Ciencias. Humanas, 30, 147-154.

Sierpe V., Prieto, A., Huidobro, C., \& Stern,C. (2009). Excavaciones arqueológicas en el sitio "Alero Quemado" (Última Esperanza, Magallanes, Chile). Magallania, 37(2), 177-189.

Silveira, M. J. (1982). Alero Las Mellizas. Patagonia Documental, 8(1), 5-23.

Silveira, M. J. (1979). Análisis e interpretación de los restos faunísticos de la Cueva Grande del Arroyo Feo. Relaciones de la Sociedad Argentina de Antropología, 13, 229-253.

Silveira, M. J. (1996). Alero Los Cipreses. En J. Gómez Otero (Ed.), Arqueología. Solo Patagonia. Ponencias de las Segundas Jornadas de Arqueología de la Patagonia, (pp. 107-118). Puerto Madryn: CENPAT-CONICET.

Silveira, M. J. (1999). El Alero Lariviére: un sitio en el bosque septentrional andino (Departamento Los Lagos, Provincia del Neuquén, Argentina). En Soplando en el viento. Actas de las III Jornadas de Arqueología de la Patagonia (pp. 83-92). NeuquénBuenos Aires: Universidad Nacional del Comahue e Instituto Nacional de Antropología y Pensamiento Latinoamericano.

Silveira, M. J., López, L. G., \& Aldazabal, V. (2014). Investigaciones arqueológicas en el alero Las Mellizas, bosque andino de Patagonia Septentrional, sudoeste de la provincia de Neuquén. Comechingonia Virtual 8(2), 157-190.

Tessone, A., Fernández, P. M., Bellelli, C., \& Panarello, H. (2014). $\delta^{13} \mathrm{C}$ and $\delta^{15} \mathrm{~N}$ characterization of modern Huemul (Hippocamelus bisulcus) from the Patagonian Andean Forest. Scope and limitations of their use as a geographical marker. International Journal of
Osteoarchaeology, 24, 219-230.

Velásquez, H., \& Adán, L. (2004). Marifilo I: evidencias arqueofaunísticas para entender las relaciones hombre y bosques templados en los sistemas lacustres cordilleranos del centro-sur de Chile. En M. T. Civalero, P. M. Fernández, \& A. G. Guráieb (Eds.), Contra viento y marea. Arqueología de Patagonia (pp. 507519). Buenos Aires: Instituto Nacional de Antropología y Pensamiento Latinoamericano y Sociedad Argentina de Antropología.

Velásquez, H., \& Trejo, V. (2005). Alero Fontana: Aprovechamiento específico del huemul. Actas de XVI Congreso Nacional de Arqueología chilena (pp. 557566). Concepción: Ediciones Escaparate.

Velásquez, M. H., \& Mena, F. (2006). Distribuciones óseas de ungulados en la cueva Baño Nuevo-1 (XI Región, Chile): un primer acercamiento. Magallania, 34(2), 91-106.

Vila, A. R., Saucedo Gálvez, C. E., Aldridge, D., Ramilo, E. \& Corti González, P. (2010). South Andean Huemul Hippocamelus bisulcus (Molina 1782). En J. M. B. Duarte \& S. González (Eds.), Neotropical cervidology: Biology and Medicine of Latin American Deer (pp. 89-100). Brazil and Switzerland: Jaboticabal, Funep and Gland and IUCN.

Walker, M. J., Berkelhammer, C. M., Bjorck, S., Cwynar, L. C., Fisher, D. A., Long, A. J., Lowe, J. J., Newnham, R. M., Rasmussen, S. O., \& Weiss, H. (2012). Formal subdivision of the Holocene series/ epoch: a discussion paper by a working group of INTIMATE (Integration of ice-core, marine and terrestrial records) and the Subcommission on Quaternary Stratigraphy (International Commission on Stratigraphy). Journal of Quaternary Science, 27(7), 649-659.

Whitlock C., Bianchi, M. M., Bartlein, P., Markgraf, V., Marlon, J., Walsh, M., \& Mc Coy N. (2006). Postglacial vegetation, climate and fire historyalong the east side of the Andes (lat 41-42.5 S), Argentina. Quaternary Research, 66, 187-201. 
